\title{
The Size Premium as a Lottery
}

\author{
Richard J. McGee ${ }^{\mathrm{a}, *}$, Jose Olmo ${ }^{\mathrm{b}, \mathrm{c}}$ \\ ${ }^{a}$ Smurfit Graduate Business School, University College Dublin, Ireland; \\ ${ }^{b}$ Department of Economic Analysis, Universidad de Zaragoza, Spain \\ ${ }^{c}$ Department of Economics, University of Southampton, UK
}

\begin{abstract}
We investigate empirically the dependence of the size effect on the top performing stocks in a cross-section of risky assets separated by industry. We propose a test for a lotterystyle factor payoff based on a stochastic utility model for an under-diversified investor. The associated conditional logit model is used to rank different investment portfolios based on size and we assess the robustness of the ranking to the inclusion/exclusion of the best performing stocks in the cross-section. Our results show that the size premium has a lottery-style payoff and is spurious for most industries once we remove the single best returning stock in an industry from the sample each month. Analysis in an asset pricing framework shows that standard asset pricing models fail to correctly specify the size premium on risky assets when industry winners are excluded from the construction of the size factor. Our findings have implications for stock picking, investment management and risk factor analysis.
\end{abstract}

Keywords: Size effect; lottery; asset pricing; industry momentum; monotonicity tests; risk factors; ranked sorted portfolios

\section{Introduction}

Firms with small market capitalization tend to outperform larger companies. Banz (1981) as well as Keim $(1983,1999)$ were among the first to document this phenomenon empirically. In particular, these authors find that risk-adjusted stock returns are a decreasing function of firm size. Fama\&MacBeth (1973) and Fama\&French (1992) exploit this negative relationship and note that firms' market capitalization has statistical power

\footnotetext{
*Email: richard.mcgee@ucd.ie
} 
to explain the cross-section of stock returns above and beyond the market portfolio. The investment literature has also exploited the size anomaly by developing portfolios based on the monotonic relationship between firms' market capitalization and stock returns aiming to capture the size premium, see Reinganum (2007) and Berk (1995), among other examples. This is usually done by constructing top-minus-bottom trading strategies that short the bottom ranked asset and invest in the top ranked asset, reaping the difference in expected returns. The literature on financial economics has also found the size anomaly to be a key factor for empirical asset pricing, see Fama\&French $(1993,2015)$ as seminal examples. In this case interest is focused on testing the explanatory power of a common size factor in pricing the excess returns on risky assets.

In this article we test whether the size factor has a lottery payoff. There is an extensive literature on the demand for positively skewed or lottery-like investment returns. Mitton \& Vorkink (2007) examine over 60,000 individual investor accounts and find that the stocks most often selected by under-diversified investors have substantially higher average skewness (in particular idiosyncratic skewness), than the stocks most often selected by diversified investors. A preference for positive skewness has long been proposed in the literature, for example, Arditti (2006) and Scott \& Horvath (1980) demonstrate that investors prefer positive skewness in return distributions under fairly general conditions. In the behavioural finance literature, Barberis \& Huang (2008) show that an implication of Tversky \& Kahneman (1992)'s cumulative prospect theory is that a security's own skewness can be priced. This might result in positively skewed securities appearing to be "overpriced" and earning a negative average excess return. Investors are attracted to lottery-like assets with positively skewed returns because they offer a very large payoff with a small probability, which the investors overweight. This demand makes positively skewed securities overpriced and likely to earn low returns.

Ilmanen (2012) describes how the highest volatility assets in an asset class often have the worst return, implying a demand for leverage or lottery-style payoffs. For example, this author shows that small-growth stocks have historically under-performed all other subsets in the Fama-French value/size classifications. In the IPO literature, Green \& Hwang 
(2012) showed that IPOs with high expected skewness have lower long-term returns (and higher first-day returns). A number of attributes have been associated with lottery-like payoffs in the literature, for example, stocks with high idiosyncratic volatility have been shown to have low returns(see Ang et al (2006); Bali et al (2011); Boyer et al (2009)). Stocks with high CAPM beta (leveraging market risk) have been consistently shown to be bad value in the literature. Frazzini \& Pedersen (2008) argue that leverage-constrained investors seeking high returns may drive demand for riskier assets, making these assets structurally overpriced.

In this article we test whether the size/market capitalization attribute, and associated factor-mimicking portfolios, receive a lottery-like payoff. The implications of this are that most small stocks do not payoff and the returns to a size strategy are driven by a small number of winners. This type of payoff can be captured through diversification but leaves an under-diversified investor (such as those in the database of Mitton \& Vorkink, 2007) exposed. The risk being that they will not include winning stocks and their resulting return expectation is negative.

To investigate the effect of winning stocks on the performance of investment portfolios based on size we propose a conditional logit model for ranking different investment portfolios based on size and assess the robustness of the ranking to the inclusion/exclusion of the best performing stocks in the cross-section ${ }^{1}$. This parametric choice is embedded within a stochastic utility model for explaining the investment decisions of under-diversified size investors aiming to exploit the so-called size premium. Under-diversified individuals maximize their expected utility in each period by choosing the stock that is predicted to yield the highest return (highest positive skew). This choice is driven by market capitalization of the portfolio and modeled parametrically using the conditional logit model proposed in McFadden (1974).

In order to obtain cross-sectional variation on the relationship between the size ef-

\footnotetext{
${ }^{1}$ The conditional logit model has been widely used to predict firm bankruptcy events (see Altman et al (2016) for a review). It has also been used (less widely) to forecast stock returns and rank stocks in Olson \& Mossman (2003) and Zhu et al. (2011). Other applications of the model include forecasting the winner of horse races in Bolton \& Chapman (1986), the choices of job seekers in Boskin (1974), and consumer choices in Chapman and Staelin (1982).
} 
fect and portfolio performance we split the whole cross-section of stocks into different industries and fit the conditional logit model to each industry separately. Investment managers in industry often apply an industry-specific approach to equity investment and this has been justified in academic literature also (see e.g. Kacperczyk et al (2005); Wu \& Mazouz (2016); Behr et al. (2012) and Moskowitz \& Grinblatt (1999) for analyses at industry level). We apply the conditional logit model at an industry-specific level across three ranked sorted portfolios based on market capitalization: a small, mid-size and big portfolio created from the stocks in each tertile of the cross-section of assets in a specific industry ranked by asset size. This exercise is repeated for 20 industries over the period July 1963 to November 2015. Our results reveal that the size effect vanishes once the top performing stocks in an industry are removed from the sample. These results are also confirmed by the monotonicity test proposed in Patton \& Timmerman (2010) (henceforth referred to as the P\&T test). Our empirical findings also highlight the role of industry momentum in determining the relationship between market capitalization and portfolio performance. Specifically, market capitalization has significantly better predictive ability for portfolio return performance in the months following a positive return in an industry than in the months following a negative industry return.

Given these findings, we investigate further the influence of the winning stocks in industry-specific size portfolios. In particular, we propose an alternative size portfolio that we denominate as the winner-weighted index, based on the forecast rank probabilities of stocks provided by the conditional logit model. Intuitively, those stocks that are predicted to be winners in the next period receive a larger allocation of wealth than those stocks that have a low probability of becoming winners. More formally, the allocation of wealth to each asset in the portfolio is determined by the forecast winning probabilities obtained from the conditional logit model and driven by asset size. The performance of this portfolio is compared against a cap-weighted index benchmark portfolio. The weights in the latter portfolio are also driven by market capitalization, however, in contrast to our winnerweighted index portfolio, smaller stocks within an industry receive a smaller allocation of wealth. We consider statistical and economic measures such as the Sharpe ratio, Sortino 
ratio, the certainty equivalent return of a mean-variance investor and portfolio turnover. We observe the existence of two regimes in portfolio performance. During positive industry momentum periods, the winner-weighted index outperforms the cap-weighted portfolio for 19 out of 20 industries, the exception being the utilities industry. This result is, however, reversed in periods of negative industry momentum for which the cap-weighted index outperforms the winner-weighted index in 18 out of 20 industries.

Our second objective is to explore the influence of winning stocks on the size portfolio pricing factor widely used in the empirical asset pricing literature, see Fama\&French (1993, 2015) and extensions given by the momentum factor of Carhart (1997) and the liquidity factor of Pastor \& Stambaugh (2003). Our empirical results for both a top-minus-bottom trading portfolio and a long-only portfolio show that standard asset pricing models are not able to adequately capture the contribution of the size premium to the overall risk premium when the winning stocks are removed from the size factor portfolio. In contrast, we note that the factor loadings ( $\beta$ 's) associated to the size portfolio pricing factor in standard models are robust to the inclusion/exclusion of the winning stocks. The removal of winning stocks is affecting the risk premium rather than the covariance of portfolios with the risk factor.

Van Dijk (2011) reviews over thirty years of research into the size effect and the ongoing debate on whether the size premium is a compensation for systematic risk. Our findings are aligned with those of researchers such as Daniel\&Titman (1997) and Heston et al. (1999) who find that stock returns are linked to firm characteristics for reasons that may have nothing to do with the covariance structure of returns. This view is shared by Chen et al (2018). These authors decompose firm size into horizon-based components, and find that size five years ago explains $80 \%$ of the current size but has little predictive power for the return. In contrast, the change in size over the prior two to five years explains only $18 \%$ of the size but completely captures the size premium. These authors also suggest that illiquidity and exposures to cash flow news and variance news are likely to be the economic drivers of the size premium. Gompers and Metrick (2001) note that small companies enjoyed a distinct return advantage over investors in large companies 
during the period 1926 to 1979. These authors find, however, that the size premium reverses in the subsequent twenty years, with large stocks earning a significant premium over small stocks since 1980. These authors attribute this stylized fact to the presence of institutional investors holding well-diversified portfolios and reducing, in turn, the relevance of under-diversified investors in financial markets.

Our findings are also consistent with those in Bessembinder (2017), who attributes the entire excess net return of the US equity market over treasuries since 1927 to just $4 \%$ of the stocks. Our work differs in that we examine the size effect, we use a novel methodology to test statistically for the dependence on extreme performers, and we narrow down the relevant extreme performers to just a single stock in each of twenty industry classifications each month. The implications of our findings are, however, similar in that they make the task of an active investor more difficult. Any decision to omit a stock through stock picking carries with it the risk that it could result in a negative size premium for the resulting size portfolio (and under-performance compared to a benchmark) if the omitted stock is an extreme performer. The increased difficulty in beating an index due to positively skewed returns was also previously highlighted in Ikenberry et al. (1998). Our association of the size effect with extreme performers is also consistent with findings in Jiang\&Yao (2013), who link the size premium with stock price jumps.

The rest of the paper is organized as follows. Section 2 discusses the data used for the empirical analysis of the size effect. Section 3 introduces a conditional logit model for predicting the ranking of industry-specific size portfolios. The section also presents an empirical study disentangling the effect of winning stocks on different size portfolios constructed for twenty U.S. industries over the period July 1963 to November 2015. Section 4 investigates the influence of industry winning stocks in a portfolio allocation exercise. The section proposes an alternative size portfolio with weights given by the predictive probabilities obtained from the conditional logit model. The performance of this portfolio is compared against a cap-weighted portfolio. Section 5 explores the size effect by studying the influence of winning stocks in standard empirical asset pricing models. Section 6 concludes. 


\section{Data}

We use CRSP data for the twenty industry groups defined by SIC code in Moskowitz \& Grinblatt (1999). The industry groupings are listed in Table 1. Two small adjustments are made to the groupings - we use contiguous SIC codes to define industries, the retail industry is split into two sub-industries from SIC code 50-52 and from 54-59, and the 'other' group from the original paper is excluded as it is a heterogeneous mix of the remaining companies so we do not treat these under a common industry grouping.

To replicate the investment universe of an industry-specific investor we use data for companies that were classified point-in-time as being in the industry (based on the CRSP SICCD code) for the period July 1963 - November 2015. We include all common stocks (ordinary equity, CRSP sharecode 10 or 11 ) in the CRSP stock files. ${ }^{2}$ To avoid survivorship bias, all de-listed stocks are included and given the CRSP de-listed return. Monthly risk factor data is obtained from the Fama \& French database on WRDS. The monthly liquidity risk factor of Pastor \& Stambaugh (2003) is also obtained from WRDS. The data set is split into an in-sample period of 315 months (July '63 to September '89) and an out-of-sample period of 314 months (October '89 to November '15).

\section{Model setup}

In this section we develop our framework for exploring the relationship between market capitalization and stock returns. Firstly, we motivate our analysis with a simple empirical exercise. Figure 1 displays the continuously compounded returns of an equally-weighted small capitalization portfolio constructed from the smallest third of stocks in six sample industries (All stocks). The average number of companies in each portfolio can be obtained from the third column of Table 1 . Figure 1 also reports the average returns of each industry-specific size portfolio as the best J performing stocks in each period, with $J=1, \ldots, 5$, are removed from the equally-weighted small capitalization portfolio. For most industries, when the top two performing stocks are removed from the portfolio the

\footnotetext{
${ }^{2}$ As many investors have a constraint preventing investment in companies below a minimum market capitalization, we test for robustness of our results to applying a filter on stocks with market cap. less than $\$ 100$ million. Our findings are robust to this filter, results are available from the authors on request.
} 
compound return becomes negative. For many industries it is sufficient to remove the single best performing stock to obtain a negative average return for the corresponding industry-specific size portfolio.

This illustration of the performance of industry-specific size portfolios sheds doubt on the profitability of investment strategies based on size. It also suggests that the concept of a monotonic size premium may be a misleading one in pricing risky assets. More specifically, Figure 1 shows that most of the assets in the small cap group do not contribute to providing a positive return on the industry-specific size portfolios. Rather, it is the contribution of the winning stock in each period that seems to determine the overall profitability of the size portfolio. In what follows, we formalize these conjectures by studying the relationship between market capitalization and stock returns using different investment portfolios based on the size anomaly. In particular, we propose a conditional logit model that provides a ranking of investment portfolios as a function of market capitalization. This parametric model also allows us to statistically test the existence of a size effect.

[Insert Figure 1 about here]

\subsection{Definition of a Lottery Factor}

To formalize our approach we propose the following definition of a lottery factor:

Definition 3.1. We define a lottery factor (or asset class) as one where the return premium for the factor is dependent on the positively skewed return of a limited number of winning assets $K$, with $K / N \rightarrow 0$, with $N$ the number of assets in the cross-section.

Excluding ex-post winning securities from the lottery factor construction results in factor returns that yield no positive return premium - the premium is dependent on the returns to the winners and non-winners as a group are bad value. Furthermore, if the factor premium is associated with an asset attribute such as size, removing the winning assets will alter the explanatory power of the attribute on returns in the remaining sample such that it is no longer statistically significant or reverses polarity. This captures the 
fact that the assets are bad value as a group with the winners excluded. This enables the presence of a lottery payoff dependence for a given factor or asset class to be tested statistically by testing the relationship between the attribute and returns when the ex-post winning securities are removed.

There are two aspects to measuring the extent to which an investment class or factor premium is driven by lottery-style payoffs: The first is the level of concentration of the premium in a small number of winning assets, i.e. the number of lottery payoffs $(K)$. The highest concentration possible being where all of the positive premium for the asset class or factor is removed by excluding a single security. In this article we perform industry level analysis on the size factor to test for a lottery-style payoff dependence by excluding the $\mathrm{N}$ best performing stocks. We examine size factor returns and perform statistical analysis on the size attribute in the remaining sample to provide metrics on the level of concentration of the size premium in the best $\mathrm{N}$ performing stocks for $\mathrm{N}=1,2,3,4,5$.

The second attribute is the magnitude of the difference between the returns including the winning assets and those excluding them. We perform a market-wide risk premium analysis on the size factor to demonstrate the drop in the premium with industry-winning stocks excluded.

\subsection{The under-diversified investor}

Here we consider the utility of an under-diversified size investor such as that of Mitton \& Vorkink (2007), who is engaged in stock picking. They are deliberately underdiversifying to maximize the skewness of their return. The under-diversified investor is looking to pick the stock with the largest return in the next period. As they are positive skew-loving they are deliberately remaining under-diversified. These individuals pick stocks according to their market capitalization and follow the investment rule that suggests the existence of an inverse relationship between stock returns and market capitalization. To formalize the preferences of these individuals we follow the statistical framework developed by McFadden (1974) and assume that at each point in time $t$, size investors' preferences for a given stock $j=1, \ldots, N$ are given by the following utility 
function

$$
U_{j, t+1}=\beta x_{j, t+1}+f_{t+1}+\varepsilon_{j, t+1},
$$

with $x_{j, t+1}=p_{j, t+1}+m_{t+1}$ denoting the natural logarithm of market capitalization of asset $j$ at time $t+1 ; p_{t+1}$ denotes the log-price of the asset and $m_{t+1}$ denotes the $\log$ of the number of outstanding shares in the market on the risky asset. For simplicity, in the following derivations we will assume the variable, $m$, to be constant over time. The variable $f$ denotes a set of unobservable factors that are common across risky assets and that capture industry characteristics; $\varepsilon_{j, t+1}$ is a random variable that represents the unobservable idiosyncratic firm characteristics influencing the return on the risky asset such that $E_{t}\left[\varepsilon_{j, t+1}\right]=0$. Furthermore, the efficient market hypothesis entails the following condition $E_{t}\left[p_{j, t+1}\right]=p_{j, t}$. Under these conditions, the natural log of market capitalization is a persistent variable that satisfies $E_{t}\left[x_{j, t+1}\right]=x_{j, t}$. For notational convenience we have $E_{t}[\cdot]=E\left[\cdot \mid \Im_{t}\right]$ to denote the expectation conditional on the sigma-algebra $\Im_{t}$ that contains all the information available to the individual at time $t$, and $P_{t}\{\cdot\}=P\left\{\cdot \mid \Im_{t}\right\}$ to denote the conditional probability of an event given $\Im_{t}$. Then

$$
E_{t}\left[U_{j, t+1}\right]=\beta x_{j, t}+E_{t}\left[f_{t+1}\right]
$$

We work in a predictive framework and assume that individuals act in a rational way, maximizing their expected utility. Let $y_{t+1}$ be a random variable taking values between 1 and $N$ describing the choice of the size investor at time $t+1$. An investor will choose the risky asset $j$ at time $t$ if $E_{t}\left[U_{j, t+1}\right]$ is the largest of $E_{t}\left[U_{1, t+1}\right], \ldots, E_{t}\left[U_{N, t+1}\right]$.

Measurement error is typical in the modeling process of $E_{t}\left[U_{j, t+1}\right]$ because the lagged value of market capitalization and the conditional expectation of the common industry component may not capture all of the factors influencing the choice process at time $t$, and individuals often exhibit aspects of idiosyncratic behavior. To incorporate this random effect, we add a random error term $v_{j, t}$ to the conditional expectation expression (2) which captures the measurement errors in the modeling process of the cross-sectional conditional expectation of the utilities of each choice. More specifically, we assume that size investors 
maximize the following function at time $t$ :

$$
V_{j, t}=E_{t}\left[U_{j, t+1}\right]+v_{j, t}
$$

with $v_{j, t}$ a zero-mean random variable. By construction, the random error $v_{j, t}$ does not belong to the information set of the individual $\Im_{t}$ such that model (3) can be interpreted as a stochastic utility model. In this scenario the probability of choosing asset $j$ may be written as

$$
P_{t}\left\{y_{t+1}=j\right\}=P\left\{\max \left(V_{1, t}, \ldots, V_{N, t}\right)=V_{j, t}\right\}
$$

Unfortunately, the choice of most distributions necessitates the calculation of numerical integrations to determine the choice probabilities. However, if the distribution of the stochastic error is assumed to be independent and identically distributed and following a Gumbel distribution, $P\left\{v_{j, t} \leq x\right\}=\exp (-\exp (-x))$, and under a set of additional axioms, McFadden (1974) shows that the choice probabilities have the following form:

$$
P_{t}\left\{y_{t+1}=j\right\}=\frac{\exp \left(E_{t}\left[U_{j, t+1}\right]\right)}{\sum_{i=1}^{N} \exp \left(E_{t}\left[U_{i, t+1}\right]\right)}
$$

Using that $E_{t}\left[U_{j, t+1}\right]=\beta x_{j, t}+E_{t}\left[f_{t+1}\right]$, we obtain a predictive probability given by

$$
P_{t}\left\{y_{t+1}=j\right\}=\frac{\exp \left(\beta x_{j, t}+E_{t}\left[f_{t+1}\right]\right)}{\sum_{i=1}^{N} \exp \left(\beta x_{i, t}+E_{t}\left[f_{t+1}\right]\right)}
$$

Now, using that $f$ is common across assets in the cross-section, we have

$$
P_{t}\left\{y_{t+1}=j\right\}=\frac{\exp \left(\beta x_{j, t}\right) \exp \left(E_{t}\left[f_{t+1}\right]\right)}{\exp \left(E_{t}\left[f_{t+1}\right]\right) \sum_{i=1}^{N} \exp \left(\beta x_{i, t}\right)}
$$

The expression $\exp \left(E_{t}\left[f_{t+1}\right]\right)$ cancels out and yields

$$
P_{t}\left\{y_{t+1}=j\right\}=\frac{\exp \left(\beta x_{j, t}\right)}{\sum_{i=1}^{N} \exp \left(\beta x_{i, t}\right)}
$$


We assume that the ex-post choice of an asset at time $t+1$ corresponds to the highest realized return in that period. By doing so, the conditional logit model aims to capture a monotonic relationship between stock returns and market capitalization. This model imposes a ranking of stocks in terms of market capitalization that is determined by the sign of the parameter $\beta$. A negative/positive value of the parameter $\beta$ entails a monotonic decreasing/increasing relationship between the probability of choosing an asset and its market capitalization. The value $\beta=0$ implies that all assets in the cross-section have the same probability of being chosen as winning stocks.

Estimation of this parameter is obtained by maximising the conditional log-likelihood function of the above probability distribution over the $N$ possible outcomes of $y_{t+1}$ for a sample of length $T$. The log-likelihood function $\mathcal{L}$ takes this form:

$$
\mathcal{L}(\beta)=-\sum_{t=1}^{T}\left[\left(\sum_{i=1}^{N} 1\left(y_{t+1}=i\right) x_{i, t}\right) \beta-\ln \left(\sum_{j=1}^{N} \exp \left(x_{j, t}\right) \beta\right)\right],
$$

with $1\left(y_{t+1}=i\right)$ an indicator function that takes the value of one when the argument is true, and zero otherwise. The maximum likelihood estimator of $\beta$ is the quantity that maximizes expression (7). McFadden (1974) also introduces the following pseudo- $R^{2}$ measure to assess the goodness of fit of the conditional logit model:

$$
\mathcal{R}^{2}=1-\frac{\mathcal{L}(\widehat{\beta})}{\mathcal{L}(0)}
$$

with $\mathcal{L}(0)$ the log-likelihood function (7) evaluated at $\beta=0$. This measure is bounded in the range $[0,1]$. Equation 6 reduces to $1 / N$ when the coefficient $\beta$ is set to zero. In this case the value of $\mathcal{R}^{2}$ is zero. As the coefficient moves from zero, the output probabilities start to move away from the uninformed prior of $1 / N$. A value of 1 is achieved when the forecast probability is one for the winning stock in each period and zero for all other stocks.

Table 2 presents the coefficient estimate $\beta$, t-stat and the $R^{2}$ value of McFadden (1974) obtained from the conditional logit model across the 20 industry groups for the full sample period. The results clearly show the negative sign and statistical significance 
of the $\beta$ parameter estimate across industries. These findings provide ample support to the existence of a size effect at industry level. These results are explored further in the subsequent empirical analysis.

\section{[Insert Table 2 about here]}

\subsection{The winning stock hypothesis}

We present an empirical application of the conditional logit model for assessing the role of industry winners on the size effect. To do this, for each industry, we construct three ranked sorted portfolios based on market capitalization: a small, mid-size and big portfolio created from the stocks in each tertile ranked by size. For consistency with other studies on the size effect, see also Perez-Quiros \& Timmerman (2000), we divide our empirical analysis into positive and negative industry momentum periods.

Table 3 reports the p-values of the monotonicity test developed in Patton \& Timmerman (2010) between the three size portfolios ${ }^{3}$. Each column presents the results of the test when the $j$ best performing stocks in the cross-section of stocks per industry are removed from the analysis. The results show overwhelming evidence of the effect of the winning stock on the ranking of portfolios. More specifically, the first column $(j=0)$ reports for most industries a statistically significant p-value. These values confirm statistically the presence of (negative) monotonicity between market capitalization and portfolio performance. However, once we remove the winning stock in each industry the p-values of the test point to statistically insignificant negative monotonicity between size and portfolio performance. The separate analysis of positive and negative industry momentum reveals differences in the impact of the winning stock between both regimes. The overall analysis of the results obtained from the P\&T monotonicity test in Table 3 suggest that the size effect is driven by the performance of the winning stocks and only in periods of positive industry momentum.

[Insert Tables 3 and 4 about here]

\footnotetext{
${ }^{3}$ Matlab code for the test is obtained from http://public.econ.duke.edu/ ap172/code.html.
} 
Table 4 reports the p-values of a t-test for the null hypothesis $H_{0}: \beta=0$ against the alternative hypothesis $H_{0}: \beta<0$, with $\beta$ the parameter in the conditional logit model driving the relationship between the probability of choosing an asset and its market capitalization. Each column presents the results of the test when the $j$ best performing stocks in the cross-section of stocks per industry are removed from the analysis. The results in Table 4 confirm the findings in Table 3 using a parametric model based on our stochastic utility framework to model the choice of size investors. There is overwhelming evidence of a winning stock effect rather than a size effect on the ranking of the three size portfolios. Once the top performing stock in an industry is removed from the analysis, the ranking of portfolios driven by the parameter $\beta$ becomes insignificant. The estimates of the $\beta_{j}$ for each industry are plotted for different values of $j$ in Figure 2. The impact of removing winning stocks in the positive regime can be clearly seen as the $\beta$ on size moves up the $y$ axis, with almost all industries yielding a positive $\beta$ once the best returning stock is removed. The impact of momentum on the size parameter is also evident with almost all of the size $\beta$ values being positive or close to zero in the negative momentum plot (indicating a reversal of the size effect).

Comparing the two sets of test results in Tables 3 and 4, the results are largely in agreement in highlighting the impact of winning stocks and the dependence of the size effect on momentum regimes. The P\&T monotonicity test rejects monotonicity for 2 out of 20 industries in the positive momentum period (Apparel and Construction) whereas our test does not reject for any of the industries. Portfolio results in the following section (see tables 5 and 6) suggest that weightings based on size work in 18 out of 20 industries in positive momentum periods, from an investment perspective. The discrepancy between the two monotonicity tests could be explained in that, whereas size may be significant in determining the best returning portfolio, the ordering of the remaining two mid-size and big portfolios may still cause the P\&T monotonicity test to reject monotonicity. 


\section{Application to Industry Portfolio Analysis}

In this section we exploit the findings of the previous section, highlighting the major role of winning stocks in establishing the size anomaly across industry size portfolios. We construct an investment portfolio denominated as the winner-weighted index portfolio, $P_{W I}$, based on the ranking of stocks provided by the conditional logit model fitted to each of the twenty industries. More formally, the allocation of wealth within this portfolio is determined by forecast probabilities that are entirely driven by the size beta parameter and stocks' market capitalization. By doing so, we propose a size portfolio with more weight on those assets that are expected to be winners in the next period. According to the conditional logit model, these assets are also those with smallest market capitalization.

For comparison purposes, we also consider a cap-weighted portfolio, $P_{M C A P}$, with weights given by assets' market capitalization divided by the sum of total market capitalization of the industry, and an industry timing strategy, $P_{W C}$, with portfolio weights that switch between $P_{W I}$ in months following a positive industry index return and $P_{M C A P}$ in months following a negative industry index return. The rationale for choosing these two regimes is the difference in performance of the size portfolio between positive and negative industry returns.

\subsection{Methodology}

The conditional logit model based on market capitalization introduced above is parameterized through maximum likelihood estimation for each industry over the positive industry momentum months in the in-sample period (Jul '63 - Sep '89). The coefficients, test statistics and goodness of fit measures for each model are given in Table 2. The selected models are used to create forecast probabilities for each stock in each industry in the out-of-sample period (Oct '89-Nov '15). These probabilities are used as weights in the winner-weighted index portfolio. The magnitude of the model coefficient $\beta$ obtained for each industry determines the spread of portfolio weights. In the limiting case $\beta=0$, the weights revert to $1 / N$. As the coefficient increases in magnitude, smaller stocks receive a heavier weighting and larger stocks a smaller weighting in the portfolio. The spread in weights is, therefore, determined both by the deviation across the industry 
from the average size and the magnitude of the model coefficient. For each industry, the out-of-sample is split into two sub-samples, consisting of months following positive and negative industry returns.

A number of metrics are used to compare portfolio performance between the winnerweighted portfolio, $P_{W I}$, the cap-weighted portfolio, $P_{M C A P}$, and a momentum-timed investment portfolio $P_{W C}$. Firstly, the Sharpe ratio is calculated as the excess return of the portfolio divided by the standard deviation of returns. The excess return is defined as the return over the risk-free rate, the one-month treasury bill rate from the Fama \& French data set, see Kenneth French's website. ${ }^{4}$ Secondly, the Sortino ratio is calculated as the excess return divided by the square root of the semivariance defined over the negative domain of returns. The assumption behind this performance metric is that investors are not averse to positive volatility or positive jumps, therefore only volatility to the downside of portfolio returns should be penalized. Thirdly, the certainty equivalent for a mean-variance investor is calculated using three risk aversion levels $C E Q(\gamma)=$ $\mu-\frac{\gamma}{2} \sigma^{2}, \gamma=1,2,3$. Fourthly, portfolio turnover is calculated for each portfolio. This is used to calculate transaction costs that are subtracted from portfolio returns before all metrics, including average returns, are calculated. Transaction costs are set at $10 \mathrm{bps}$ and 25 bps. Detailed results are presented for 10 bps as these reflect contemporary levels of transaction costs. Summary results are provided for transaction costs of 25 bps with more detailed results available from the authors upon request. Finally, a regression of portfolio returns on the five Fama\&French (2015) factors; the momentum factor of Carhart (1997); the liquidity factor of Pastor \& Stambaugh (2003) and the relevant cap-weighted industry index returns is run. The intercept $\alpha$ of the regression and its p-value are reported for each portfolio.

\subsection{Empirical Results}

Table 5 shows the out-of-sample results (net of transaction costs of 25 bps deducted from portfolio returns before all metrics are computed) for each of the 20 industries in

\footnotetext{
${ }^{4} \mathrm{http}: / / \mathrm{mba}$.tuck.dartmouth.edu/pages/faculty/ken.french/data_library.html
} 
the positive momentum periods - the months following a positive monthly return in the industry. The winner-weighted portfolio outperforms across all metrics for 18 out of 20 industries, the exceptions being Transportation and Apparel industries. ${ }^{5}$ There is a positive $\alpha$ in the eight risk factor regression for all 20 industry portfolios and of those ten are significant at the $1 \%$ level, eleven are significant at the $5 \%$ level and sixteen at the $10 \%$ level.

Table 6 shows the out-of-sample results (net of transaction costs of 25 bps deducted from portfolio returns before all metrics are computed) for each of the twenty industries in the negative momentum periods - the months following a negative monthly return in the industry. The winner-weighted index portfolio under-performs across all metrics for nineteen out of twenty industries (the only exception is the Primary Metals industry). There is negative $\alpha$ for the regression of the portfolio returns on the eight risk factor returns for sixteen industries, with four of the $\alpha$ 's statistically significant at the $1 \%$ level, ten at the $5 \%$ level and eleven at the $10 \%$ level.

[Insert Tables 5 and 6 about here]

Table 7 shows the out-of-sample results (net of transaction costs of 25 bps deducted from portfolio returns before all metrics are computed) for the momentum-timed investment strategy, $P_{W C}$, that invests in the winner-weighted index in months following a positive industry return and in the cap-weighted index following a negative industry return. The strategy outperforms the other two portfolios in eighteen out of twenty industries in terms of Sharpe ratio. There is a positive $\alpha$ in the eight risk factor regression in all industries except for Apparel. Of those positive $\alpha$ 's, eight are statistically significant at the $1 \%$ level, nine at the $5 \%$ level and twelve at the $10 \%$ level. There is a noticeable difference between the Sharpe and Sortino ratios for the strategy. For example, the Sortino ratio is almost double the Sharpe ratio for many industries. This captures the fact that the small sized companies are experiencing positive jumps, these add to volatility in the Sharpe ratio but are ignored in the Sortino ratio as only the volatility of negative returns

\footnotetext{
${ }^{5}$ The Transportation industry outperforms for all metrics except for the Sharpe ratio.
} 
is penalized.

[Insert Table 7 about here]

The difference in performance between the timing portfolio $P_{W C}$ and the winnerweighted portfolio $P_{W I}$ is handicapped by increased transaction costs when the switching between the positive and negative regimes is taken into account. Switching from overweighting small stocks in positive momentum regimes back to weighting them on their market capitalization in negative momentum regimes drives a lot of turnover. The level of turnover is industry-specific and has two main drivers, the spread in capitalization across an industry and the level of trending or mean reversion in the industry returns. Longer trends reduce the re-balancing costs monthly and vice versa. The timed strategy also benefits from large capitalization stock gains when the market capitalization portfolio is used in negative momentum regimes. For example, the Transportation industry momentum-timed portfolio, $P_{W C}$, is picking up on the positive returns $(4.64 \%)$ for the cap-weighted portfolio in negative momentum regimes and the large returns $(26.4 \%)$ of the winner-weighted portfolio in positive momentum regimes. With transaction costs included, the strategy nets out at an annualized return of $15.5 \%$ compared to $11.0 \%$ for the cap-weighted portfolio, $P_{M C A P}$, and $11.2 \%$ for the size-weighted portfolio, $P_{W I}$.

\section{The size effect and winning stocks for asset pricing}

Given the above findings suggesting that the size effect is regime-specific and mainly driven by a small group of top-performing stocks, we conduct an empirical exercise to assess the influence of winning stocks in asset pricing. In particular, we are interested in studying the robustness of different size portfolios, with and without the winning stocks, as pricing factors in popular asset pricing models.

We construct two ranked, sorted portfolios based on market capitalization: a longshort portfolio, $P_{S M B}$, and a long-only portfolio $P_{S}$. For ease of interpretation and to match common investment practice in creating practical quantitative investment factors (see e.g. Grinold \& Kahn (2000) and Qian et al. (2007)), we create our long-short size portfolio, $P_{S M B}$, by buying the smallest third of stocks in the cross-section of risky assets 
in the investment universe and selling the largest third of stocks. ${ }^{6}$ Our long-only portfolio, $P_{S}$, is an equal-weighted portfolio that invests in the smallest third of stocks in the crosssection of risky assets in the investment universe.

\subsection{Risk Factor Regression Analysis}

Table 8 reports the parameter estimates from a risk factor analysis to assess the exposure of different investment portfolios on popular pricing factors proposed in the empirical asset pricing literature. We investigate the influence of the size effect through the following four investment portfolios: $i$ ) a cap-weighted index portfolio given by a weighted combination of all the assets in the investment universe, $i i$ ) our long-short size portfolio, $P_{S M B}$, iii) our long-only strategy $P_{S}$, and $i v$ ) a portfolio that replicates the Fama \& French size factor $F F_{S M B}$. We adopt a seven factor model to explain the returns on these portfolios. This model consists of the Fama \& French five factor model (Fama\&French (2015)) including the market factor: $M K T$, the FF size factor: $F F$, a value factor: $H M L$, an operating profitability factor: $R M W$, and an investment factor: $C M A$. We also add a momentum factor (see Carhart (1997)): $M O M O$, and the liquidity factor of Pastor \& Stambaugh (2003): $L I Q$. The time series regression equation is

$$
\begin{aligned}
r_{t}^{P} & =\alpha+\beta_{M K T}\left(r_{M K T, t}-r_{f, t}\right)+\beta_{F F} r_{F F} \\
& +\beta_{H M L} r_{H M L, t}+\beta_{R M W} r_{R M W, t}+\beta_{C M A} r_{C M A, t} \\
& +\beta_{M O M O} r_{M O M O, t}+\beta_{L I Q} r_{L I Q, t}+\epsilon_{t},
\end{aligned}
$$

with $\epsilon_{t}$ a zero-mean error term uncorrelated with the pricing factors; $r_{t}^{P}$ denotes the returns of the four investment strategies under investigation. We do this for two investment universes: $i$ ) all stocks in our twenty industry database (investment universe), and $i i$ ) all stocks excluding the industry winner for each of the 20 industry classifications. For our size portfolios $P_{S M B}$ and $P_{S}$ we also regress the portfolio returns against all the risk factors excluding the Fama-French size factor, $r_{F F}$. This leaves a total of twelve models that we

\footnotetext{
${ }^{6}$ This differs from the Fama \& French size factor, $F F_{S M B}$, in that they also control in their factor construction for the other factor exposures corresponding to stock value, operating profitability and investment.
} 
report in Table 8. Our performance measure is the regression intercept $\alpha$. Theoretically, the intercept captures the expected value of the risk-free rate over the evaluation period. The remaining $\beta$ parameters reflect the exposure of the portfolios to the pricing factors. P-values are in brackets below the parameter estimates.

\subsection{Discussion of empirical results}

The first row of Table 8 shows a regression of our cap-weighted index from all of the stocks in our investment universe against the seven risk factors. The average of the riskfree rate, $r_{f}$, over the period is $4.00 \%$ annualized. This value is close to the estimate of $4.17 \%$ that we obtain from the estimate of $\alpha$ for the first regression model. The slight difference between these values might be introduced by our reduced investment universe, namely, the selection of stocks in the 20 industries and exclusion of the stocks outside the industry definition. Row 2 of Table 8 shows that removing the industry winners in our database of risky stocks does not noticeably change the exposure of the cap-weighted index portfolio to any of the included risk factors. However, the difference between the estimate of the intercept and the average risk-free rate is negative (a drop of $0.45 \%$ annual return when the industry winners are excluded from the market cap-weighted index). This empirical finding highlights that the industry winners do not dominate the overall performance of the cap-weighted portfolio. Row 11 reports the results for the FamaFrench size factor portfolio, $F F_{S M B}$. The portfolio has statistically significant exposure to the market $\left(\beta_{M K T}\right)$, to the profitability factor $\left(\beta_{R M W}\right)$ and to the investment factor $\left(\beta_{R M W}\right)$. The intercept $\alpha$ captures a premium of $3.02 \%$ not explained by the other six risk factors. When we reconstruct the Fama French SMB factor from a data set excluding winning stocks $\left(F F_{S M B}^{*}\right)$ the intercept in a regression on all other risk factors indicates that the factor premium is not statistically significant ( $\mathrm{p}$ value 0.28 ).

The following analysis focuses specifically on our size portfolios $P_{S M B}$ and $P_{S}$. Rows 3 to 6 report the results for the long-short portfolio $P_{S M B}$ and rows 7 to 10 the results for the long-only portfolio $P_{S}$. The results in Model 4 show staggering differences in the intercept parameter estimates between the model that considers all stocks and the model that drops the industry-winning stocks from the investment universe. Whereas the 
exposures to the risk factors are very similar across investment scenarios, the estimates of the intercepts are not (with an $8 \%$ swing from $+4.05 \%$ to $-4.01 \%$ ). The results in rows 6 and 7 are similar to those in rows 4 and 5 , in this case, however, the $\alpha$ parameter estimates are higher as they also capture the size premium/exposure to the FF size factor $S M B$.

\section{[Insert Table 8 about here]}

Rows 7 to 10 report the results for the long-only portfolio $P_{S}$. The results are very similar to those already discussed for the $P_{S M B}$ portfolio and highlight the importance of considering the industry-winning stocks in the investment universe. In particular, Table 8 shows that for the portfolio $P_{S}$, the above asset pricing model reports a large statistically significant intercept of $8.4 \%$ annual return when regressed against all other risk factors, and $12.03 \%$ annual return when $F F_{S M B}$ is excluded. These results are overwhelmingly superior to $-0.02 \%$ and $3.16 \%$ obtained when the industry-winning stock is removed from the analysis (for each of 20 industries). The magnitude of the impact of the industrywinning stocks on $P_{S}$ is illustrated in Figure 3, where the cumulative returns to investing in $P_{S}$ with and without the industry-winning stock returns are plotted ${ }^{7}$.

\section{[Insert Figure 3 about here]}

The results in this section show clearly the contribution of industry winning stocks in explaining the size premium on risky assets. In particular, we show that when the winning stocks are removed from the size factor portfolio the corresponding asset pricing model is unable to adequately capture the size premium. In contrast, we note that the factor loadings associated with the size portfolio pricing factor are robust to the inclusion/exclusion of the winning stocks. Their removal is not altering the risk factor loadings of the portfolios, yet the return premia disappear.

\footnotetext{
${ }^{7}$ The results obtained for portfolio $P_{S}$ are not directly comparable to the $\alpha$ estimates obtained for the portfolio $P_{S M B}$. In contrast to the latter portfolio, the long-only portfolio needs to be adjusted by the return of an equivalent investment in a risk-free asset over the same period. $P_{S M B}$ is a net zero investment portfolio, therefore it does not need to be adjusted for an equivalent investment return at the risk-free rate.
} 


\section{Conclusion}

In this paper we investigate empirically the dependence of the size effect on the top performing stocks in a cross-section of risky assets separated by industry. To do this, we propose a test for a lottery-style factor payoff based on a stochastic utility model for an under-diversified investor. The associated conditional logit model is used to rank different investment portfolios based on size and we assess the robustness of the ranking to the inclusion/exclusion of the best performing stocks in the cross-section.

In a comprehensive empirical exercise, we have shown that the size effect produces a size premium at industry level for 19 out of the 20 industries under study. However, we observe that the profitability of size portfolios rapidly deteriorates once the top performing stocks are excluded from the investment portfolios. This stylized fact suggests that the size effect is spurious once the winning stocks are removed from the analysis. We also find a prominent role of industry momentum in the profitability of the size effect. To exploit this empirical finding, we have proposed a momentum-timed investment strategy given by portfolio weights that switch between a winner-weighted portfolio, with weights obtained from the probability forecasts of the conditional logit model, and a cap-weighted portfolio during positive and negative industry momentum, respectively. We show the outperformance of this strategy over the winner-weighted and cap-weighted portfolios in both positive and negative momentum regimes.

The application of this analysis to asset pricing provides interesting empirical findings on the importance of winning stocks for asset pricing. In particular, we have found that standard asset pricing models fail to correctly specify the risk premium on risky assets when the industry winners are excluded from the construction of the market-wide size factor portfolio. 


\section{Acknowledgements}

The authors would like to thank participants at the 2018 Workshop on Recent Developments in Financial Data Science and Econometrics (Loughborough, UK); at the Econometrics for Finance conference (JEF'2018, Morocco); at the Infiniti 2017 conference (Spain) and colleagues at a seminar in the University of Southampton for comments and suggestions on earlier versions of the paper.

Altman, E. I., Iwanicz-Drozdowska, M., Laitinen, E. K., \& Suvas, A., Financial Distress Prediction in an International Context: A Review and Empirical Analysis of Altman's Z-Score Model. Journal of International Financial Management 86 Accounting, 2016.

Ang, A., Hodrick, R. J., Xing, Y. \& Zhang, X., The cross-section of volatility and expected returns. Journal of Finance, 2006, 61(1), 259-299.

Arditti, F. D., Risk and the required return on equity. Journal of Finance, 1967, 22(1), $19-36$.

Bali, T. G., Cakici N. \& Whitelaw R. F., Maxing out: Stocks as lotteries and the crosssection of expected returns. Journal of Financial Economics, 2011, 99(2), 427-446.

Banz, R. W., The Relationship between Return and Market Value of Common Stocks. Journal of Financial Economics, 1981, 9(1), 3-18.

Barberis, N. and Huang, M., Stocks as lotteries: The implications of probability weighting for security prices. American Economic Review, 2008, 98(5), 2066-2100.

Behr, P., Guettler, A., and Truebenbach, F., Using industry momentum to improve portfolio performance. Journal of Banking \& Finance, 2012, 36(5), 1414-1423.

Berk, J. B., A critique of size-related anomalies. The Review of Financial Studies, 1995, $8(2), 275-286$.

Bessembinder, H., Do Stocks Outperform Treasury Bills? Journal of Financial Economics, Forthcoming 2018. 
Bolton, R., \& Chapman, R., Searching for positive returns at the track: a multinomial conditional logit model for handicapping horse races. Management Science, 1986, 32(8), 1040-1060.

Boskin, M. J., A conditional conditional logit model of occupational choice. Journal of Political Economy, 1984, 82(2), 389-398.

Boyer, B., Mitton, T. \& Vorkink, K., Expected idiosyncratic skewness. The Review of Financial Studies, 2009, 23(1), 169-202.

Carhart M. M., On persistence in mutual fund performance. The Journal of Finance, $1997,52(1), 57-82$.

Chapman, R. G. \& Staelin, R., Exploiting rank ordered choice set data within the stochastic utility model. Journal of Marketing Research, 1982, 288-301.

Chen, Z. \& Li, J., and Wang, H., Is the Size Premium Really Driven by Firm Size. Available at http://dx.doi.org/10.2139/ssrn.2899944

Gompers, P.A. \& Metrick, A., Institutional investors and equity prices. The Quarterly Journal of Economics, 116(1), 229-259.

Daniel, K. \& Titman, S., Evidence on the characteristics of cross sectional variation in stock returns. Journal of Finance, 1997, 52(1), 1-33.

Fama, E. F., \& French, K. R., The cross-section of expected stock returns. Journal of Finance, 1992, 67, 427-465.

Fama, E. F., \& French, K. R., Common risk factors in the returns on stocks and bonds. Journal of Financial Economics, 1993, 33(1), 3-56.

Fama, E. F., \& French, K. R., A five-factor asset pricing model. Journal of Financial Economics, 2015, 116(1), 1-22.

Fama, E. F., \& MacBeth, J. D., Risk, return, and equilibrium: empirical tests. Journal of Political Economy, 1973, 81, 607-636. 
Frazzini, A. \& Pedersen, L. H., Betting against beta. Journal of Financial Economics, 2014, 111(1), 1-25.

Green, T. C. \& Hwang, B-H, Initial public offerings as lotteries: Skewness preference and first-day returns. Management Science, 2012, 58(2), 432-444.

Grinold, R. C., \& Kahn, R. N., Active Portfolio Management, 2000, McGraw-Hill, New York.

Heston, S. L., Rouwenhorst, K. G., \& Wessels, R. E., The Role of Beta and Size in the Cross-Section of European Stock Returns. European Financial Management, 1999, $5(1), 9-27$.

Ikenberry, D. L., Shockley, R. L., \& Womack, K. L., Why active fund managers often underperform the S\&P 500: The impact of size and skewness. The Journal of Wealth Management, 1998, 1(1), 13-26.

Ilmanen, A., Do financial markets reward buying or selling insurance and lottery tickets? Financial Analysts Journal, 2012, 68(5), 26.

Jiang, G.J., \& Yao, T., Stock price jumps and cross-sectional return predictability. Journal of Financial and Quantitative Analysis, 2013, 48(05), 1519-1544.

Kacperczyk, M., Clemens S., \& Zheng, L., On the industry concentration of actively managed equity mutual funds. The Journal of Finance, 2005, 60(4), 1983-2011.

Keim, D. B., Size-Related Anomalies and Stock Return Seasonality: Further Empirical Evidence. Journal of Financial Economics, 1983, 12(1), 13-32.

Keim, D. B., An analysis of mutual fund design: the case of investing in small-cap stocks. Journal of Financial Economics, 1999, 51(2), 173-194.

McFadden, D., Conditional logit Analysis of Qualitative Choice Behavior. Frontiers in Econometrics, 1974, 303-328. 
Mitton, T. and Vorkink, K., Equilibrium underdiversification and the preference for skewness. The Review of Financial Studies, 2007, 20(4), 1255-1288.

Moskowitz, T. J., \& Grinblatt, M., Do industries explain momentum? The Journal of Finance, 1999, 54(4), 1249-90.

Olson, D., \& Mossman, C., Neural network forecasts of Canadian stock returns using accounting ratios. International Journal of Forecasting, 2003, 19(3), 453-465.

Pastor, L., \& Stambaugh, R. F., Liquidity risk and expected stock returns. Journal of Political Economy, 2003, 111(3), 642-685.

Patton, A. J., \& Timmermann, A., Monotonicity in asset returns: New tests with applications to the term structure, the CAPM, and portfolio sorts. Journal of Financial Economics, 2010, 98(3), 605-625.

Perez-Quiros, G. and Timmermann, A., Firm size and cyclical variations in stock returns. The Journal of Finance, 2000, 55(3), 1229-1262.

Qian, E., Hua, R. and Sorensen, E., Quantitative Equity Portfolio Management, 2007, Chapman \& Hall/CRC, London.

Reinganum, M. R., Misspecification of capital asset pricing: Empirical anomalies based on earnings' yields and market values. Journal of Financial Economics, 1981, 9(1), 19-46.

Scott, R. C. \& Horvath, P. A., On the direction of preference for moments of higher order than the variance. The Journal of Finance, 1980, 35(4), 915-919.

Tversky, A. \& Kahneman, D., Advances in prospect theory: Cumulative representation of uncertainty. Journal of Risk and uncertainty, 1992, 5(4), 297-323.

Van Dijk, Mathijs A, Is size dead? A review of the size effect in equity returns. Journal of Banking \& Finance, 2011, 35(12), 3263-3274.

Wu, Yuliang, and Khelifa M. Long-term industry reversals. Journal of Banking E⿱ Finance, 2016, 68, 236-250. 
Zhu, M., Philpotts, D., Sparks, R., \& Stevenson, M. J., A hybrid approach to combining CART and logistic regression for stock ranking. Journal of Portfolio Management, 2011, 38(1), 100. 


\begin{tabular}{|c|c|c|c|c|}
\hline Industry Name & $\begin{array}{l}\text { SIC } \\
\text { Codes }\end{array}$ & $\begin{array}{l}\text { Ave. Num. } \\
\text { Companies }\end{array}$ & $\begin{array}{l}\text { Ave. } \% \text { of } \\
\text { Mkt. Cap. }\end{array}$ & $\begin{array}{c}\text { Ave. } \\
\text { Return }\end{array}$ \\
\hline 1. Mining & $10-14$ & $330.67(123)$ & $4.98 \%$ & 0.012 \\
\hline 2. Food & $20-20$ & $126.80(84)$ & $4.20 \%$ & 0.012 \\
\hline 3. Apparel & $22-23$ & $94.52(25)$ & $0.53 \%$ & 0.009 \\
\hline 4. Paper & $26-26$ & $52.33(25)$ & $1.77 \%$ & 0.012 \\
\hline 5. Chemical & 28 & $294.90(127)$ & 10.11 & 0.01 \\
\hline 6. Petroleum & 29 & $35.81(26)$ & $7.14 \%$ & 0.014 \\
\hline 7. Construction & 32 & $46.33(14)$ & $0.69 \%$ & 0.010 \\
\hline 8. Prim. Metals & 33 & $82.36(49)$ & $1.57 \%$ & 0.010 \\
\hline 9. Fab. Metals & 34 & $100.64(40)$ & $0.99 \%$ & 0.013 \\
\hline 10. Machinery & 35 & $290.05(143)$ & $6.87 \%$ & 0.012 \\
\hline 11. Electrical Eq. & 36 & $381.67(164)$ & $6.11 \%$ & 0.013 \\
\hline 12. Transportation Eq. & 37 & $107.37(78)$ & $4.10 \%$ & 0.012 \\
\hline 13. Manufacturing & $38-39$ & $291.10(69)$ & $3.74 \%$ & 0.013 \\
\hline 14. Railroads & 40 & $16.99(9)$ & $0.75 \%$ & 0.014 \\
\hline 15. Other Transport. & $41-47$ & $113.05(51)$ & 1.276 & 0.010 \\
\hline 16. Utilities & 49 & $187.44(115)$ & $6.15 \%$ & 0.010 \\
\hline 17. Retail 1 & $50-52$ & $196.36(48)$ & $1.53 \%$ & 0.011 \\
\hline 18. Dept. Stores & 53 & $47.15(15)$ & $2.60 \%$ & 0.011 \\
\hline 19. Retail 2 & $54-59$ & $253.63(94)$ & $2.53 \%$ & 0.011 \\
\hline 20. Financial & $60-69$ & $1511.18(152)$ & $15.5 \%$ & 0.010 \\
\hline 21. Other & & $1272.70(219)$ & $16.81 \%$ & 0.012 \\
\hline
\end{tabular}

Table 1: Industry Descriptive statistics: Descriptive statistics for the set of industries analyzed over the period July ' 63 to Nov '15. The industry definitions based on SIC codes are taken from Moskowitz \& Grinblatt (1999). The sum of the market capitalization of all included securities was $\$ 21$ trillion in Nov '15. 


\begin{tabular}{|c|c|c|c|c|c|c|c|}
\hline Industry & Size Coef & t-stat & $R^{2}(\%)$ & Industry & Size Coef & t-stat & $R^{2}(\%)$ \\
\hline Mining & -0.41 & -19.07 & 4.92 & Electrical Eq. & -0.36 & -14.90 & 3.25 \\
\hline Food & -0.40 & -18.38 & 6.47 & Transportation Eq. & -0.38 & -17.74 & 5.85 \\
\hline Apparel & -0.34 & -13.33 & 3.35 & Manufacturing & -0.39 & -15.00 & 3.56 \\
\hline Paper & -0.32 & -16.57 & 5.68 & Railroads & -0.18 & -9.48 & 2.61 \\
\hline Chemical & -0.40 & -18.67 & 5.38 & Other Transport & -0.38 & -16.18 & 4.56 \\
\hline Petroleum & -0.34 & -18.40 & 8.18 & Utilities & -0.56 & -25.61 & 10.28 \\
\hline Construction & -0.25 & -11.24 & 2.79 & Retail1 & -0.40 & -15.80 & 4.24 \\
\hline Prim. Metals & -0.29 & -13.26 & 3.13 & Dept. Stores & -0.27 & -15.29 & 4.85 \\
\hline Fab. Metals & -0.37 & -14.90 & 4.23 & Retail2 & -0.44 & -18.46 & 5.23 \\
\hline Machinery & -0.40 & -16.65 & 4.41 & Financial & -0.47 & -18.86 & 4.25 \\
\hline
\end{tabular}

Table 2: Industry-specific conditional logic model parameters: for size factor models over the full sample of July 1963 to November 2015. The $R^{2}$ refers to the goodness of fit measure of McFadden (1974). 


\begin{tabular}{|c|c|c|c|c|c|c|c|c|c|c|c|c|}
\hline & \multicolumn{6}{|c|}{ Positive Industry Momentum } & \multicolumn{6}{|c|}{ Negative Industry Momentum } \\
\hline & \# Months & $\mathrm{j}=0$ & $\mathrm{j}=1$ & $\mathrm{j}=2$ & $\mathrm{j}=3$ & $\mathrm{j}=4$ & \# Months & $\mathrm{j}=0$ & $\mathrm{j}=1$ & $\mathrm{j}=2$ & $\mathrm{j}=3$ & $\mathrm{j}=4$ \\
\hline Mining & 372 & $0.010^{* * *}$ & $0.037^{* *}$ & 0.141 & 0.306 & 0.763 & 256 & 1.000 & 1.000 & 1.000 & 1.000 & 1.000 \\
\hline Food & 393 & $0.071^{*}$ & 0.999 & 1.000 & 1.000 & 1.000 & 235 & 0.951 & 1.000 & 1.000 & 1.000 & 1.000 \\
\hline Apparel & 358 & 0.157 & 1.000 & 1.000 & 1.000 & 1.000 & 270 & 1.000 & 1.000 & 1.000 & 1.000 & 1.000 \\
\hline Paper & 362 & $0.000^{* * *}$ & 1.000 & 1.000 & 1.000 & 1.000 & 266 & 0.994 & 1.000 & 1.000 & 1.000 & 1.000 \\
\hline Chemical & 385 & $0.000^{* * *}$ & 0.271 & 0.942 & 0.999 & 1.000 & 243 & 1.000 & 1.000 & 1.000 & 1.000 & 1.000 \\
\hline Petroleum & 371 & $0.000^{* * *}$ & 1.000 & 1.000 & 1.000 & 1.000 & 257 & 0.780 & 1.000 & 1.000 & 1.000 & 1.000 \\
\hline Construction & 361 & 0.490 & 0.988 & 1.000 & 1.000 & 1.000 & 267 & 0.996 & 1.000 & 1.000 & 1.000 & 1.000 \\
\hline Prim. Metals & 341 & $0.030^{* *}$ & 0.966 & 1.000 & 1.000 & 1.000 & 287 & 0.579 & 1.000 & 1.000 & 1.000 & 1.000 \\
\hline Fab. Metals & 370 & $0.000^{* * *}$ & 0.798 & 0.992 & 1.000 & 1.000 & 258 & 0.949 & 1.000 & 1.000 & 1.000 & 1.000 \\
\hline Machinery & 354 & $0.000^{* * *}$ & $0.032^{* *}$ & 0.873 & 0.999 & 1.000 & 274 & 0.882 & 1.000 & 1.000 & 1.000 & 1.000 \\
\hline Electrical Eq. & 360 & $0.000^{* * *}$ & $0.000^{* * *}$ & $0.094^{*}$ & 0.748 & 0.979 & 268 & 1.000 & 1.000 & 1.000 & 1.000 & 1.000 \\
\hline Transportation & 365 & $0.002^{* * *}$ & 1.000 & 1.000 & 1.000 & 1.000 & 263 & 0.997 & 1.000 & 1.000 & 1.000 & 1.000 \\
\hline Manufacturing & 374 & $0.000^{* * *}$ & $0.006^{* * *}$ & 0.266 & 0.729 & 0.980 & 254 & 1.000 & 1.000 & 1.000 & 1.000 & 1.000 \\
\hline Railroads & 369 & $0.000^{* * *}$ & 1.000 & 1.000 & 1.000 & 1.000 & 259 & 0.925 & 1.000 & 1.000 & 1.000 & 1.000 \\
\hline Other Transport & 374 & $0.024^{* *}$ & 0.997 & 1.000 & 1.000 & 1.000 & 254 & 0.997 & 1.000 & 1.000 & 1.000 & 1.000 \\
\hline Utilities & 369 & $0.000^{* * *}$ & 0.966 & 1.000 & 1.000 & 1.000 & 259 & 0.922 & 1.000 & 1.000 & 1.000 & 1.000 \\
\hline Retail 1 & 379 & $0.000^{* * *}$ & 0.476 & 0.996 & 1.000 & 1.000 & 249 & 1.000 & 1.000 & 1.000 & 1.000 & 1.000 \\
\hline Dept. Stores & 357 & $0.036^{* *}$ & 0.999 & 1.000 & 1.000 & 1.000 & 271 & 0.999 & 1.000 & 1.000 & 1.000 & 1.000 \\
\hline Retail 2 & 366 & $0.007^{* * *}$ & 0.854 & 1.000 & 1.000 & 1.000 & 262 & 1.000 & 1.000 & 1.000 & 1.000 & 1.000 \\
\hline Financial & 389 & $0.007^{* * *}$ & $0.011^{* *}$ & $0.087^{*}$ & 0.250 & 0.589 & 239 & 1.000 & 1.000 & 1.000 & 1.000 & 1.000 \\
\hline
\end{tabular}

Table 3: P-values for the Patton and Timmerman Monotonicity test for each industry in positive and negative industry momentum regimes, and with $\mathrm{j}=0$ to 4 of the top returning stocks removed over the full data sample (Jul '63 - Nov '15). Monotonicity testing is carried out across three ranked sorted portfolios based on market capitalization, a small, mid-size and big portfolio created form the stocks in each tertile ranked by size. ${ }^{* * *}$ denotes $p<0.01,{ }^{* *}$ denotes $p<0.05$ and ${ }^{*}$ denotes $p<0.1$, i.e. statistically significant monotonicity at the $1 \%, 5 \%$ or $10 \%$ level. None of the values for any industry are statistically significant in the negative industry momentum period. When the single best returning stock in each industry is removed only five industries exhibit statistical significance in the positive momentum regime, this reduces further to only two industries when the two best returning stocks are removed. 


\begin{tabular}{|c|c|c|c|c|c|c|c|c|c|c|c|c|}
\hline & \multicolumn{6}{|c|}{ Positive Industry Momentum } & \multicolumn{6}{|c|}{ Negative Industry Momentum } \\
\hline & \# Months & $\mathrm{j}=0$ & $j=1$ & $\mathrm{j}=2$ & $j=3$ & $\mathrm{j}=4$ & \# Months & $\mathrm{j}=0$ & $j=1$ & $\mathrm{j}=2$ & $\mathrm{j}=3$ & $\mathrm{j}=4$ \\
\hline Mining & 372 & $0.000^{* * *}$ & 1.000 & 1.000 & 1.000 & 1.000 & 256 & 1.000 & 1.000 & 1.000 & 1.000 & 1.000 \\
\hline Food & 393 & $0.000^{* * *}$ & 1.000 & 1.000 & 1.000 & 1.000 & 235 & 1.000 & 1.000 & 1.000 & 1.000 & 1.000 \\
\hline Apparel & 358 & $0.000^{* * *}$ & 1.000 & 1.000 & 1.000 & 1.000 & 270 & 1.000 & 1.000 & 1.000 & 1.000 & 1.000 \\
\hline Paper & 362 & $0.000^{* * *}$ & $0.011^{* *}$ & $0.000^{* * *}$ & 1.000 & 1.000 & 266 & 1.000 & 1.000 & 1.000 & 1.000 & 1.000 \\
\hline Chemical & 385 & $0.000^{* * *}$ & 1.000 & 1.000 & 1.000 & 1.000 & 243 & 1.000 & 1.000 & 1.000 & 1.000 & 1.000 \\
\hline Petroleum & 371 & $0.000^{* * *}$ & 1.000 & 1.000 & 1.000 & 1.000 & 257 & 1.000 & 1.000 & 1.000 & 1.000 & 1.000 \\
\hline Construction & 361 & $0.000^{* * *}$ & 1.000 & 1.000 & 1.000 & 1.000 & 267 & 1.000 & 1.000 & 1.000 & 1.000 & 1.000 \\
\hline Prim. Metals & 341 & $0.000^{* * *}$ & 0.399 & 1.000 & 1.000 & 1.000 & 287 & 1.000 & 1.000 & 1.000 & 1.000 & 1.000 \\
\hline Fab. Metals & 370 & $0.000^{* * *}$ & 1.000 & 1.000 & 1.000 & 1.000 & 258 & 1.000 & 1.000 & 1.000 & 1.000 & 1.000 \\
\hline Machinery & 354 & $0.000^{* * *}$ & 1.000 & 1.000 & 1.000 & 1.000 & 274 & 1.000 & 1.000 & 1.000 & 1.000 & 1.000 \\
\hline Electrical Eq. & 360 & $0.000^{* * *}$ & 1.000 & 1.000 & 1.000 & 1.000 & 268 & 1.000 & 1.000 & 1.000 & 1.000 & 1.000 \\
\hline Transportation & 365 & $0.000^{* * *}$ & 1.000 & 1.000 & 1.000 & 1.000 & 263 & 1.000 & 1.000 & 1.000 & 1.000 & 1.000 \\
\hline Manufacturing & 374 & $0.000^{* * *}$ & 1.000 & 1.000 & 1.000 & 1.000 & 254 & 1.000 & 1.000 & 1.000 & 1.000 & 1.000 \\
\hline Railroads & 369 & $0.000^{* * *}$ & 1.000 & 1.000 & 0.985 & 1.000 & 259 & 1.000 & 1.000 & 1.000 & 1.000 & 1.000 \\
\hline Other Transport & 374 & $0.000^{* * *}$ & 1.000 & 1.000 & 1.000 & 1.000 & 254 & 1.000 & 1.000 & 1.000 & 1.000 & 1.000 \\
\hline Utilities & 369 & $0.000^{* * *}$ & 1.000 & 1.000 & 1.000 & 1.000 & 259 & $0.000^{* * *}$ & 1.000 & 1.000 & 1.000 & 1.000 \\
\hline Retail 1 & 379 & $0.000^{* * *}$ & 1.000 & 1.000 & 1.000 & 1.000 & 249 & 1.000 & 1.000 & 1.000 & 1.000 & 1.000 \\
\hline Dept. Stores & 357 & $0.000^{* * *}$ & 1.000 & 1.000 & 1.000 & 1.000 & 271 & 1.000 & 1.000 & 1.000 & 1.000 & 1.000 \\
\hline Retail 2 & 366 & $0.000^{* * *}$ & 1.000 & 1.000 & 1.000 & 1.000 & 262 & 1.000 & 1.000 & 1.000 & 1.000 & 1.000 \\
\hline Financial & 389 & $0.000^{* * *}$ & 1.000 & 1.000 & 1.000 & 1.000 & 239 & 1.000 & 1.000 & 1.000 & 1.000 & 1.000 \\
\hline
\end{tabular}

Table 4: P-values based on the test described in Section 3.2 on the polarity of size parameters, $\beta_{j}<0$, based on the industry-specific conditional logit models over the full data sample (Jul '63 - Nov '15). In each industry, on each month, three equal-weighted portfolios are formed from the top third, middle third and bottom third of stocks ranked on market capitalization. The logarithm of the portfolio market cap of the resulting portfolios is then used in a conditional logistic model to forecast the size portfolio with the largest return in the month. The process is repeated in each industry with the $\mathrm{j}$ best returning stocks removed in each sample with $\mathrm{j}=0,1,2,3,4$. The test is carried out on the sets of $\beta_{j}$, the size parameters obtained for the cond. logit model in each sample. ${ }^{* * *}$ denotes $p<0.01,{ }^{* *}$ denotes $p<0.05$ and * denotes $p<0.1$, i.e. statistically significant negative parameters on size at the $1 \%, 5 \%$ or $10 \%$ level. 


\begin{tabular}{|c|c|c|c|c|c|c|c|c|c|c|c|c|c|}
\hline Industry & Portfolio & $\begin{array}{l}\text { Sample Size } \\
\text { (\# Months) }\end{array}$ & $\begin{array}{c}\mu \\
(\%)\end{array}$ & $\begin{array}{c}\sigma \\
(\%)\end{array}$ & SR & Sortino & $\begin{array}{c}\text { CEQ1 } \\
(\%)\end{array}$ & $\begin{array}{c}\text { CEQ2 } \\
(\%)\end{array}$ & $\begin{array}{c}\text { CEQ3 } \\
(\%)\end{array}$ & $\begin{array}{c}\text { BTO } \\
(\%)\end{array}$ & $\begin{array}{l}\text { STO } \\
(\%)\end{array}$ & $\begin{array}{c}\alpha \\
(\%)\end{array}$ & $\mathrm{p} \operatorname{val}(\alpha)$ \\
\hline \multirow[t]{2}{*}{ Mining } & $P_{W I}$ & 176 & 53.52 & 49.77 & 1.02 & 3.02 & 41.14 & 28.75 & 16.36 & 19.29 & 18.73 & $23.47^{*}$ & 0.06 \\
\hline & $P_{M C A P}$ & 176 & 10.94 & 20.04 & 0.40 & 0.77 & 8.93 & 6.92 & 4.91 & 3.77 & 3.20 & - & - \\
\hline \multirow[t]{2}{*}{ Food } & $P_{W I}$ & 201 & 21.30 & 23.66 & 0.78 & 1.64 & 18.50 & 15.70 & 12.91 & 13.35 & 12.85 & $17.66^{* * *}$ & 0.01 \\
\hline & $P_{M C A P}$ & 201 & 10.47 & 12.33 & 0.61 & 0.93 & 9.71 & 8.95 & 8.19 & 2.18 & 1.69 & - & - \\
\hline \multirow[t]{2}{*}{ Apparel } & $P_{W I}$ & 177 & 15.44 & 30.23 & 0.42 & 0.77 & 10.87 & 6.30 & 1.73 & 15.49 & 14.93 & 0.46 & 0.95 \\
\hline & $P_{M C A P}$ & 177 & 11.57 & 17.58 & 0.50 & 0.93 & 10.02 & 8.48 & 6.93 & 3.56 & 3.00 & - & - \\
\hline \multirow[t]{2}{*}{ Paper } & $P_{W I}$ & 188 & 38.13 & 30.88 & 1.14 & 3.47 & 33.36 & 28.60 & 23.83 & 12.55 & 12.02 & $24.28^{* * *}$ & 0.00 \\
\hline & $P_{M C A P}$ & 188 & 12.51 & 17.20 & 0.56 & 1.05 & 11.04 & 9.56 & 8.08 & 3.02 & 2.49 & - & - \\
\hline \multirow[t]{2}{*}{ Chemical } & $P_{W I}$ & 200 & 39.21 & 31.33 & 1.16 & 2.41 & 34.30 & 29.39 & 24.48 & 18.25 & 17.75 & $25.86^{* * *}$ & 0.00 \\
\hline & $P_{M C A P}$ & 200 & 10.83 & 12.61 & 0.62 & 1.00 & 10.03 & 9.24 & 8.44 & 3.02 & 2.52 & - & - \\
\hline \multirow[t]{2}{*}{ Petroleum } & $P_{W I}$ & 187 & 23.95 & 26.18 & 0.80 & 2.00 & 20.52 & 17.10 & 13.67 & 10.12 & 9.58 & $11.94^{*}$ & 0.06 \\
\hline & $P_{M C A P}$ & 187 & 9.17 & 15.38 & 0.41 & 0.73 & 7.98 & 6.80 & 5.62 & 1.90 & 1.36 & - & - \\
\hline \multirow[t]{2}{*}{ Construction } & $P_{W I}$ & 182 & 31.97 & 34.39 & 0.84 & 2.09 & 26.05 & 20.14 & 14.22 & 13.13 & 12.58 & $16.17^{*}$ & 0.08 \\
\hline & $P_{M C A P}$ & 182 & 17.98 & 24.81 & 0.61 & 0.81 & 14.91 & 11.83 & 8.75 & 4.00 & 3.46 & - & - \\
\hline \multirow[t]{2}{*}{ Prim. Metals } & $P_{W I}$ & 169 & 24.90 & 29.43 & 0.74 & 1.41 & 20.56 & 16.23 & 11.90 & 12.79 & 12.20 & 10.28 & 0.15 \\
\hline & $P_{M C A P}$ & 169 & 13.60 & 23.16 & 0.45 & 0.96 & 10.92 & 8.24 & 5.55 & 3.95 & 3.36 & - & - \\
\hline \multirow[t]{2}{*}{ Fab. Metals } & $P_{W I}$ & 194 & 46.17 & 41.32 & 1.05 & 2.96 & 37.63 & 29.10 & 20.56 & 16.44 & 15.92 & $35.45^{* * *}$ & 0.00 \\
\hline & $P_{M C A P}$ & 194 & 11.25 & 15.14 & 0.55 & 0.74 & 10.11 & 8.96 & 7.81 & 3.40 & 2.88 & - & - \\
\hline \multirow[t]{2}{*}{ Machinery } & $P_{W I}$ & 184 & 38.22 & 30.72 & 1.15 & 2.55 & 33.50 & 28.78 & 24.06 & 19.28 & 18.74 & $24.56^{* * *}$ & 0.00 \\
\hline & $P_{M C A P}$ & 184 & 12.34 & 21.85 & 0.43 & 0.64 & 9.95 & 7.57 & 5.18 & 3.73 & 3.19 & - & - \\
\hline \multirow[t]{2}{*}{ Electrical Eq. } & $P_{W I}$ & 184 & 43.72 & 32.55 & 1.25 & 2.46 & 38.43 & 33.13 & 27.83 & 20.14 & 19.60 & $28.12^{* * *}$ & 0.00 \\
\hline & $P_{M C A P}$ & 184 & 11.12 & 22.55 & 0.36 & 0.47 & 8.58 & 6.03 & 3.49 & 3.24 & 2.70 & - & - \\
\hline \multirow[t]{2}{*}{ Transportation } & $P_{W I}$ & 187 & 26.36 & 31.10 & 0.75 & 1.61 & 21.53 & 16.69 & 11.86 & 13.87 & 13.34 & 8.20 & 0.34 \\
\hline & $P_{M C A P}$ & 187 & 15.27 & 16.27 & 0.76 & 1.28 & 13.95 & 12.62 & 11.30 & 2.80 & 2.27 & - & - \\
\hline \multirow[t]{2}{*}{ Manufacturing } & $P_{W I}$ & 191 & 47.82 & 34.50 & 1.30 & 4.20 & 41.87 & 35.92 & 29.97 & 18.50 & 17.98 & $26.43^{* * *}$ & 0.00 \\
\hline & $P_{M C A P}$ & 191 & 12.96 & 14.64 & 0.68 & 1.24 & 11.89 & 10.81 & 9.74 & 4.19 & 3.67 & - & - \\
\hline \multirow[t]{2}{*}{ Railroads } & $P_{W I}$ & 189 & 30.84 & 30.50 & 0.92 & 3.17 & 26.19 & 21.54 & 16.88 & 7.81 & 7.28 & $14.69^{*}$ & 0.08 \\
\hline & $P_{M C A P}$ & 189 & 17.36 & 18.35 & 0.80 & 1.37 & 15.67 & 13.99 & 12.31 & 2.86 & 2.33 & - & - \\
\hline \multirow[t]{2}{*}{ Other Transport } & $P_{W I}$ & 186 & 23.54 & 32.63 & 0.63 & 1.53 & 18.22 & 12.90 & 7.57 & 15.28 & 14.74 & 7.45 & 0.38 \\
\hline & $P_{M C A P}$ & 186 & 10.33 & 16.43 & 0.46 & 0.74 & 8.99 & 7.64 & 6.29 & 3.58 & 3.04 & - & - \\
\hline \multirow[t]{2}{*}{ Utilities } & $P_{W I}$ & 195 & 28.75 & 26.92 & 0.96 & 2.22 & 25.13 & 21.51 & 17.88 & 15.05 & 14.53 & $25.68^{* * *}$ & 0.00 \\
\hline & $P_{M C A P}$ & 195 & 11.27 & 12.86 & 0.65 & 0.99 & 10.45 & 9.62 & 8.79 & 2.53 & 2.02 & - & - \\
\hline \multirow[t]{2}{*}{ Retail 1} & $P_{W I}$ & 192 & 38.91 & 30.16 & 1.19 & 2.68 & 34.36 & 29.81 & 25.27 & 18.81 & 18.29 & $21.81^{* * *}$ & 0.01 \\
\hline & $P_{M C A P}$ & 192 & 13.92 & 14.83 & 0.74 & 1.35 & 12.82 & 11.72 & 10.62 & 3.59 & 3.07 & - & - \\
\hline \multirow[t]{2}{*}{ Dept. Stores } & $P_{W I}$ & 181 & 25.26 & 38.67 & 0.58 & 1.10 & 17.79 & 10.31 & 2.84 & 13.99 & 13.44 & $20.82^{* *}$ & 0.05 \\
\hline & $P_{M C A P}$ & 181 & 11.53 & 18.91 & 0.45 & 0.70 & 9.74 & 7.95 & 6.16 & 1.96 & 1.41 & - & - \\
\hline \multirow[t]{2}{*}{ Retail 2} & $P_{W I}$ & 182 & 36.38 & 33.23 & 1.01 & 2.18 & 30.86 & 25.34 & 19.82 & 19.53 & 18.98 & $15.23^{*}$ & 0.07 \\
\hline & $P_{M C A P}$ & 182 & 14.54 & 14.23 & 0.83 & 1.59 & 13.53 & 12.52 & 11.51 & 3.62 & 3.07 & - & - \\
\hline \multirow[t]{2}{*}{ Financial } & $P_{W I}$ & 196 & 25.35 & 17.28 & 1.30 & 3.45 & 23.86 & 22.37 & 20.87 & 13.72 & 13.21 & $15.01^{* * *}$ & 0.00 \\
\hline & $P_{M C A P}$ & 196 & 13.49 & 13.22 & 0.80 & 1.25 & 12.61 & 11.74 & 10.87 & 2.86 & 2.35 & - & - \\
\hline
\end{tabular}

Table 5: Out of sample portfolio performance (October '89 to November '15), positive momentum: comparison of the returns to a probability-weighted portfolio, $P_{W I}$, constructed using probabilities from a size based forecasting model (fit in-sample), and a cap-weighted index, $P_{M C A P}$. Performance is measured in months following a positive return month for each industry. All numbers, including returns, are reported net of transaction costs of $25 \mathrm{bps}$ deducted monthly from the raw returns using the appropriate portfolio turnover figures. 


\begin{tabular}{|c|c|c|c|c|c|c|c|c|c|c|c|c|c|}
\hline Industry & Portfolio & $\begin{array}{l}\text { Sample Size } \\
\text { (\# Months) }\end{array}$ & $\begin{array}{c}\mu \\
(\%)\end{array}$ & $\begin{array}{c}\sigma \\
(\%)\end{array}$ & SR & Sortino & $\begin{array}{c}\text { CEQ1 } \\
(\%)\end{array}$ & $\begin{array}{c}\text { CEQ2 } \\
(\%)\end{array}$ & $\begin{array}{c}\text { CEQ3 } \\
(\%)\end{array}$ & $\begin{array}{l}\text { BTO } \\
(\%)\end{array}$ & $\begin{array}{l}\mathrm{STO} \\
(\%)\end{array}$ & $\begin{array}{c}\alpha \\
(\%)\end{array}$ & $\mathrm{p} \operatorname{val}(\alpha)$ \\
\hline \multirow[t]{2}{*}{ Mining } & $P_{W I}$ & 137 & 4.06 & 38.45 & 0.03 & 0.05 & -3.33 & -10.73 & -18.12 & 19.51 & 18.78 & -5.65 & 0.53 \\
\hline & $P_{M C A P}$ & 137 & 6.81 & 27.49 & 0.14 & 0.19 & 3.03 & -0.75 & -4.53 & 6.05 & 5.32 & & \\
\hline \multirow[t]{2}{*}{ Food } & $P_{W I}$ & 112 & 12.06 & 18.61 & 0.49 & 0.65 & 10.32 & 8.59 & 6.86 & 13.75 & 12.85 & 4.44 & 0.45 \\
\hline & $P_{M C A P}$ & 112 & 13.82 & 15.82 & 0.69 & 0.82 & 12.57 & 11.32 & 10.07 & 3.96 & 3.07 & & \\
\hline \multirow[t]{2}{*}{ Apparel } & $P_{W I}$ & 136 & -13.39 & 27.47 & -0.60 & -0.74 & -17.16 & -20.93 & -24.70 & 15.15 & 14.42 & $-13.34^{* *}$ & 0.05 \\
\hline & $P_{M C A P}$ & 136 & 2.93 & 26.06 & -0.00 & -0.00 & -0.46 & -3.86 & -7.25 & 4.37 & 3.64 & & \\
\hline \multirow[t]{2}{*}{ Paper } & $P_{W I}$ & 125 & -14.31 & 29.54 & -0.58 & -0.86 & -18.67 & -23.04 & -27.40 & 11.28 & 10.48 & $-21.35^{* * *}$ & 0.00 \\
\hline & $P_{M C A P}$ & 125 & 5.74 & 19.25 & 0.15 & 0.19 & 3.89 & 2.03 & 0.18 & 4.29 & 3.49 & & \\
\hline \multirow[t]{2}{*}{ Chemical } & $P_{W I}$ & 113 & 11.02 & 36.32 & 0.23 & 0.46 & 4.42 & -2.18 & -8.77 & 21.13 & 20.25 & -1.23 & 0.91 \\
\hline & $P_{M C A P}$ & 113 & 14.39 & 16.35 & 0.71 & 1.16 & 13.05 & 11.72 & 10.38 & 4.62 & 3.74 & & \\
\hline \multirow[t]{2}{*}{ Petroleum } & $P_{W I}$ & 126 & 9.43 & 26.50 & 0.24 & 0.37 & 5.91 & 2.40 & -1.11 & 10.91 & 10.12 & 0.89 & 0.91 \\
\hline & $P_{M C A P}$ & 126 & 15.05 & 18.21 & 0.67 & 1.11 & 13.39 & 11.73 & 10.07 & 3.03 & 2.24 & & \\
\hline \multirow[t]{2}{*}{ Construction } & $P_{W I}$ & 131 & -16.32 & 26.15 & -0.73 & -1.05 & -19.74 & -23.16 & -26.58 & 11.87 & 11.10 & $-17.64^{* * *}$ & 0.01 \\
\hline & $P_{M C A P}$ & 131 & -2.94 & 31.24 & -0.19 & -0.23 & -7.82 & -12.70 & -17.57 & 5.95 & 5.19 & & \\
\hline \multirow[t]{2}{*}{ Prim. Metals } & $P_{W I}$ & 144 & 24.54 & 120.48 & 0.18 & 1.14 & -48.04 & -120.62 & -193.20 & 12.66 & 11.96 & 21.36 & 0.56 \\
\hline & $P_{M C A P}$ & 144 & 1.19 & 30.12 & -0.05 & -0.06 & -3.34 & -7.88 & -12.41 & 5.27 & 4.58 & & \\
\hline \multirow[t]{2}{*}{ Fab. Metals } & $P_{W I}$ & 119 & 6.15 & 22.19 & 0.14 & 0.21 & 3.68 & 1.22 & -1.24 & 13.15 & 12.31 & -4.09 & 0.53 \\
\hline & $P_{M C A P}$ & 119 & 15.48 & 23.05 & 0.54 & 0.68 & 12.82 & 10.17 & 7.51 & 5.78 & 4.94 & & \\
\hline \multirow[t]{2}{*}{ Machinery } & $P_{W I}$ & 129 & 6.74 & 34.08 & 0.11 & 0.21 & 0.93 & -4.88 & -10.69 & 19.15 & 18.37 & -8.32 & 0.28 \\
\hline & $P_{M C A P}$ & 129 & 13.34 & 25.50 & 0.41 & 0.62 & 10.09 & 6.84 & 3.58 & 5.06 & 4.28 & & \\
\hline \multirow[t]{2}{*}{ Electrical Eq. } & $P_{W I}$ & 129 & 5.78 & 36.80 & 0.08 & 0.16 & -0.99 & -7.76 & -14.54 & 19.87 & 19.09 & $-15.33^{* *}$ & 0.04 \\
\hline & $P_{M C A P}$ & 129 & 12.25 & 27.15 & 0.35 & 0.50 & 8.56 & 4.88 & 1.19 & 5.13 & 4.35 & & \\
\hline \multirow[t]{2}{*}{ Transportation } & $P_{W I}$ & 126 & -11.04 & 25.88 & -0.54 & -0.81 & -14.39 & -17.74 & -21.09 & 14.09 & 13.29 & $-16.06^{* * *}$ & 0.01 \\
\hline & $P_{M C A P}$ & 126 & 4.64 & 24.24 & 0.07 & 0.09 & 1.70 & -1.24 & -4.17 & 4.04 & 3.25 & & \\
\hline \multirow[t]{2}{*}{ Manufacturing } & $P_{W I}$ & 122 & -1.60 & 25.74 & -0.17 & -0.27 & -4.91 & -8.22 & -11.53 & 18.52 & 17.70 & $-11.48^{*}$ & 0.07 \\
\hline & $P_{M C A P}$ & 122 & 11.20 & 20.32 & 0.41 & 0.58 & 9.14 & 7.07 & 5.01 & 5.37 & 4.55 & & \\
\hline \multirow[t]{2}{*}{ Railroads } & $P_{W I}$ & 124 & -0.71 & 23.65 & -0.16 & -0.21 & -3.51 & -6.31 & -9.10 & 8.82 & 8.02 & -7.70 & 0.25 \\
\hline & $P_{M C A P}$ & 124 & 10.87 & 21.38 & 0.36 & 0.56 & 8.59 & 6.30 & 4.02 & 4.15 & 3.35 & & \\
\hline \multirow[t]{2}{*}{ Other Transport } & $P_{W I}$ & 127 & -7.08 & 24.49 & -0.41 & -0.59 & -10.08 & -13.08 & -16.08 & 14.06 & 13.28 & $-12.04^{* *}$ & 0.05 \\
\hline & $P_{M C A P}$ & 127 & 5.53 & 20.41 & 0.12 & 0.15 & 3.45 & 1.36 & -0.72 & 5.31 & 4.53 & & \\
\hline \multirow[t]{2}{*}{ Utilities } & $P_{W I}$ & 118 & 5.11 & 23.30 & 0.09 & 0.15 & 2.39 & -0.32 & -3.03 & 14.20 & 13.35 & 4.21 & 0.55 \\
\hline & $P_{M C A P}$ & 118 & 4.63 & 14.82 & 0.12 & 0.15 & 3.53 & 2.43 & 1.33 & 4.00 & 3.16 & & \\
\hline \multirow[t]{2}{*}{ Retail 1} & $P_{W I}$ & 121 & -0.87 & 28.21 & -0.14 & -0.23 & -4.85 & -8.83 & -12.80 & 19.50 & 18.67 & $-15.62^{* *}$ & 0.05 \\
\hline & $P_{M C A P}$ & 121 & 10.90 & 19.57 & 0.40 & 0.56 & 8.98 & 7.06 & 5.15 & 5.86 & 5.03 & & \\
\hline \multirow[t]{2}{*}{ Dept. Stores } & $P_{W I}$ & 132 & -12.07 & 28.37 & -0.52 & -0.85 & -16.09 & -20.12 & -24.14 & 11.28 & 10.53 & $-18.55^{* *}$ & 0.03 \\
\hline & $P_{M C A P}$ & 132 & 10.79 & 18.46 & 0.43 & 0.71 & 9.08 & 7.38 & 5.68 & 2.76 & 2.01 & & \\
\hline \multirow[t]{2}{*}{ Retail 2} & $P_{W I}$ & 131 & -10.17 & 24.72 & -0.54 & -0.75 & -13.22 & -16.28 & -19.34 & 17.28 & 16.52 & $-18.05^{* * *}$ & 0.00 \\
\hline & $P_{M C A P}$ & 131 & 6.88 & 19.59 & 0.19 & 0.27 & 4.96 & 3.04 & 1.12 & 4.67 & 3.91 & & \\
\hline \multirow[t]{2}{*}{ Financial } & $P_{W I}$ & 117 & -5.73 & 14.09 & -0.62 & -0.74 & -6.72 & -7.71 & -8.70 & 15.01 & 14.16 & $-7.32^{* *}$ & 0.02 \\
\hline & $P_{M C A P}$ & 117 & 5.14 & 21.24 & 0.10 & 0.14 & 2.88 & 0.62 & -1.63 & 4.84 & 3.99 & & \\
\hline
\end{tabular}

Table 6: Out of sample portfolio performance (October '89 to November '15), negative momentum: comparison of the returns to a probability-weighted portfolio, $P_{W I}$, constructed using probabilities from a size based forecasting model (fit in-sample), and a cap-weighted index, $P_{M C A P}$. Performance is measured in months following a negative return month for each industry. All numbers, including returns, are reported net of transaction costs of $25 \mathrm{bps}$ deducted monthly from the raw returns using the appropriate portfolio turnover figures. 


\begin{tabular}{|c|c|c|c|c|c|c|c|c|c|c|c|c|c|}
\hline Industry & Portfolio & $\begin{array}{l}\text { Sample Size } \\
\text { (\# Months) }\end{array}$ & $\begin{array}{c}\mu \\
(\%)\end{array}$ & $\begin{array}{c}\sigma \\
(\%)\end{array}$ & SR & Sortino & $\begin{array}{c}\text { CEQ1 } \\
(\%)\end{array}$ & $\begin{array}{c}\text { CEQ2 } \\
(\%)\end{array}$ & $\begin{array}{c}\text { CEQ3 } \\
(\%)\end{array}$ & $\begin{array}{c}\text { BTO } \\
(\%)\end{array}$ & $\begin{array}{l}\text { STO } \\
(\%)\end{array}$ & $\begin{array}{c}\alpha \\
(\%) \\
\end{array}$ & $\mathrm{p} \operatorname{val}(\alpha)$ \\
\hline & $P_{W C}$ & 313 & 30.60 & 42.01 & 0.66 & 1.51 & 21.77 & 12.95 & 4.13 & 52.20 & 51.88 & $12.72^{*}$ & 0.08 \\
\hline \multirow[t]{3}{*}{ Mining } & $P_{W I}$ & 313 & 32.37 & 49.51 & 0.59 & 1.29 & 20.11 & 7.86 & -4.40 & 17.60 & 17.28 & 13.73 & 0.14 \\
\hline & $P_{M C A P}$ & 313 & 9.13 & 23.56 & 0.26 & 0.39 & 6.35 & 3.58 & 0.80 & 2.23 & 1.91 & & \\
\hline & $P_{W C}$ & 313 & 16.11 & 21.24 & 0.62 & 1.11 & 13.86 & 11.60 & 9.35 & 50.45 & 50.13 & $8.37^{* *}$ & 0.05 \\
\hline \multirow[t]{3}{*}{ Food } & $P_{W I}$ & 313 & 18.53 & 22.39 & 0.70 & 1.24 & 16.02 & 13.52 & 11.01 & 11.99 & 11.67 & $14.13^{* * *}$ & 0.00 \\
\hline & $P_{M C A P}$ & 313 & 11.67 & 13.66 & 0.64 & 0.86 & 10.73 & 9.80 & 8.87 & 1.10 & 0.78 & & \\
\hline & $P_{W C}$ & 313 & 7.74 & 28.58 & 0.17 & 0.27 & 3.66 & -0.43 & -4.51 & 46.51 & 46.19 & -2.05 & 0.65 \\
\hline \multirow[t]{3}{*}{ Apparel } & $P_{W I}$ & 313 & 3.23 & 29.92 & 0.01 & 0.02 & -1.24 & -5.71 & -10.19 & 13.69 & 13.37 & -4.09 & 0.46 \\
\hline & $P_{M C A P}$ & 313 & 7.82 & 21.67 & 0.23 & 0.32 & 5.47 & 3.12 & 0.77 & 1.37 & 1.05 & & \\
\hline & $P_{W C}$ & 313 & 23.12 & 27.23 & 0.74 & 1.63 & 19.41 & 15.71 & 12.00 & 42.15 & 41.83 & $12.17^{* * *}$ & 0.01 \\
\hline \multirow[t]{3}{*}{ Paper } & $P_{W I}$ & 313 & 16.83 & 32.22 & 0.43 & 0.84 & 11.64 & 6.45 & 1.26 & 10.73 & 10.41 & 6.61 & 0.27 \\
\hline & $P_{M C A P}$ & 313 & 9.81 & 18.04 & 0.38 & 0.58 & 8.18 & 6.55 & 4.93 & 1.44 & 1.12 & & \\
\hline & $P_{W C}$ & 313 & 27.89 & 27.13 & 0.92 & 1.84 & 24.21 & 20.53 & 16.85 & 50.90 & 50.58 & $14.84^{* * *}$ & 0.01 \\
\hline \multirow[t]{3}{*}{ Chemical } & $P_{W I}$ & 313 & 29.76 & 33.91 & 0.79 & 1.64 & 24.01 & 18.26 & 12.51 & 17.42 & 17.10 & $17.23^{* * *}$ & 0.01 \\
\hline & $P_{M C A P}$ & 313 & 12.11 & 14.06 & 0.65 & 1.04 & 11.12 & 10.14 & 9.15 & 1.48 & 1.16 & & \\
\hline & $P_{W C}$ & 313 & 17.93 & 23.30 & 0.64 & 1.38 & 15.21 & 12.50 & 9.79 & 46.68 & 46.36 & 4.49 & 0.24 \\
\hline \multirow[t]{3}{*}{ Petroleum } & $P_{W I}$ & 313 & 17.88 & 27.01 & 0.55 & 1.04 & 14.23 & 10.59 & 6.94 & 8.99 & 8.67 & 7.11 & 0.16 \\
\hline & $P_{M C A P}$ & 313 & 11.53 & 16.57 & 0.52 & 0.90 & 10.16 & 8.79 & 7.41 & 1.02 & 0.70 & & \\
\hline & $P_{W C}$ & 313 & 15.26 & 33.42 & 0.37 & 0.63 & 9.67 & 4.09 & -1.50 & 42.67 & 42.35 & 4.55 & 0.38 \\
\hline \multirow[t]{3}{*}{ Construction } & $P_{W I}$ & 313 & 11.50 & 32.16 & 0.27 & 0.52 & 6.33 & 1.16 & -4.01 & 10.92 & 10.61 & 2.53 & 0.67 \\
\hline & $P_{M C A P}$ & 313 & 9.23 & 27.79 & 0.23 & 0.29 & 5.37 & 1.50 & -2.36 & 2.09 & 1.77 & & \\
\hline & $P_{W C}$ & 313 & 11.72 & 29.87 & 0.29 & 0.43 & 7.26 & 2.80 & -1.67 & 44.78 & 44.46 & 3.40 & 0.35 \\
\hline \multirow[t]{3}{*}{ Prim. Metals } & $P_{W I}$ & 313 & 30.70 & 111.64 & 0.25 & 1.59 & -31.61 & -93.93 & -156.24 & 11.49 & 11.17 & 23.06 & 0.32 \\
\hline & $P_{M C A P}$ & 313 & 7.89 & 26.60 & 0.19 & 0.26 & 4.35 & 0.81 & -2.72 & 1.95 & 1.63 & & \\
\hline & $P_{W C}$ & 313 & 32.13 & 35.74 & 0.82 & 1.79 & 25.74 & 19.36 & 12.97 & 49.76 & 49.44 & $19.37^{* * *}$ & 0.00 \\
\hline \multirow[t]{3}{*}{ Fab. Metals } & $P_{W I}$ & 313 & 32.42 & 36.67 & 0.80 & 1.91 & 25.70 & 18.97 & 12.25 & 14.45 & 14.13 & $22.54^{* * *}$ & 0.00 \\
\hline & $P_{M C A P}$ & 313 & 12.86 & 18.52 & 0.54 & 0.68 & 11.14 & 9.43 & 7.71 & 1.81 & 1.49 & & \\
\hline & $P_{W C}$ & 313 & 25.48 & 28.91 & 0.78 & 1.47 & 21.30 & 17.12 & 12.95 & 52.77 & 52.45 & $12.48^{* * *}$ & 0.00 \\
\hline \multirow[t]{3}{*}{ Machinery } & $P_{W I}$ & 313 & 25.88 & 33.74 & 0.68 & 1.37 & 20.19 & 14.50 & 8.81 & 17.89 & 17.58 & 9.07 & 0.11 \\
\hline & $P_{M C A P}$ & 313 & 12.75 & 23.39 & 0.42 & 0.62 & 10.02 & 7.28 & 4.55 & 1.56 & 1.24 & & \\
\hline & $P_{W C}$ & 313 & 28.40 & 30.77 & 0.83 & 1.45 & 23.67 & 18.94 & 14.20 & 50.98 & 50.66 & $16.13^{* * *}$ & 0.00 \\
\hline \multirow[t]{3}{*}{ Electrical Eq. } & $P_{W I}$ & 313 & 28.83 & 35.63 & 0.73 & 1.41 & 22.48 & 16.13 & 9.79 & 18.85 & 18.53 & $13.17^{* *}$ & 0.02 \\
\hline & $P_{M C A P}$ & 313 & 11.58 & 24.51 & 0.35 & 0.48 & 8.58 & 5.58 & 2.57 & 1.57 & 1.26 & & \\
\hline & $P_{W C}$ & 313 & 15.48 & 28.76 & 0.44 & 0.75 & 11.34 & 7.21 & 3.07 & 44.02 & 43.70 & 3.20 & 0.49 \\
\hline \multirow[t]{3}{*}{ Transportation } & $P_{W I}$ & 313 & 11.18 & 29.83 & 0.28 & 0.51 & 6.73 & 2.28 & -2.17 & 12.52 & 12.20 & 0.40 & 0.94 \\
\hline & $P_{M C A P}$ & 313 & 10.99 & 19.89 & 0.41 & 0.53 & 9.01 & 7.04 & 5.06 & 1.30 & 0.98 & & \\
\hline & $P_{W C}$ & 313 & 31.18 & 30.25 & 0.93 & 2.24 & 26.61 & 22.03 & 17.45 & 50.69 & 50.37 & $15.44^{* * *}$ & 0.00 \\
\hline Manufacturing & $P_{W I}$ & 313 & 28.99 & 32.27 & 0.81 & 1.81 & 23.78 & 18.58 & 13.37 & 16.83 & 16.51 & $13.49^{* *}$ & 0.02 \\
\hline & $P_{M C A P}$ & 313 & 12.27 & 17.05 & 0.55 & 0.82 & 10.82 & 9.37 & 7.91 & 2.11 & 1.79 & & \\
\hline & $P_{W C}$ & 313 & 20.83 & 27.31 & 0.66 & 1.58 & 17.10 & 13.37 & 9.64 & 39.71 & 39.39 & 6.55 & 0.20 \\
\hline Railroads & $P_{W I}$ & 313 & 18.42 & 28.32 & 0.55 & 1.08 & 14.41 & 10.40 & 6.39 & 6.67 & 6.36 & 7.14 & 0.21 \\
\hline & $P_{M C A P}$ & 313 & 14.79 & 19.59 & 0.61 & 0.98 & 12.87 & 10.95 & 9.03 & 1.46 & 1.14 & & \\
\hline & $P_{W C}$ & 313 & 13.99 & 28.42 & 0.39 & 0.76 & 9.95 & 5.92 & 1.88 & 46.42 & 46.10 & 3.10 & 0.52 \\
\hline Other Transport & $P_{W I}$ & 313 & 10.73 & 31.22 & 0.25 & 0.51 & 5.86 & 0.99 & -3.89 & 13.83 & 13.51 & -0.16 & 0.98 \\
\hline & $P_{M C A P}$ & 313 & 8.38 & 18.13 & 0.30 & 0.41 & 6.74 & 5.10 & 3.45 & 1.67 & 1.35 & & \\
\hline & $P_{W C}$ & 313 & 17.51 & 23.36 & 0.62 & 1.26 & 14.78 & 12.05 & 9.32 & 45.11 & 44.79 & $11.79^{* * *}$ & 0.01 \\
\hline Utilities & $P_{W I}$ & 313 & 20.92 & 29.80 & 0.60 & 1.13 & 16.48 & 12.04 & 7.60 & 14.22 & 13.90 & $18.04^{* * *}$ & 0.00 \\
\hline & $P_{M C A P}$ & 313 & 8.77 & 13.64 & 0.43 & 0.60 & 7.84 & 6.91 & 5.98 & 1.29 & 0.97 & & \\
\hline & $P_{W C}$ & 313 & 25.71 & 26.88 & 0.85 & 1.65 & 22.10 & 18.49 & 14.87 & 51.03 & 50.71 & $13.00^{* * *}$ & 0.01 \\
\hline Retail 1 & $P_{W I}$ & 313 & 23.82 & 30.08 & 0.69 & 1.36 & 19.30 & 14.78 & 10.25 & 17.00 & 16.68 & 9.17 & 0.11 \\
\hline & $P_{M C A P}$ & 313 & 12.75 & 16.80 & 0.59 & 0.88 & 11.34 & 9.93 & 8.52 & 1.78 & 1.47 & & \\
\hline & $P_{W C}$ & 313 & 16.79 & 31.87 & 0.44 & 0.79 & 11.71 & 6.63 & 1.55 & 47.59 & 47.27 & 8.26 & 0.19 \\
\hline Dept. Stores & $P_{W I}$ & 313 & 9.37 & 37.48 & 0.17 & 0.32 & 2.35 & -4.67 & -11.69 & 11.68 & 11.36 & 3.00 & 0.70 \\
\hline & $P_{M C A P}$ & 313 & 11.21 & 18.69 & 0.44 & 0.71 & 9.47 & 7.72 & 5.97 & 0.76 & 0.44 & & \\
\hline & $P_{W C}$ & 313 & 21.74 & 28.67 & 0.66 & 1.28 & 17.63 & 13.52 & 9.41 & 49.62 & 49.31 & $8.31^{*}$ & 0.08 \\
\hline Retail 2 & $P_{W I}$ & 313 & 17.01 & 31.01 & 0.45 & 0.83 & 12.20 & 7.40 & 2.59 & 16.70 & 16.38 & 3.88 & 0.49 \\
\hline & $P_{M C A P}$ & 313 & 11.33 & 16.69 & 0.50 & 0.76 & 9.94 & 8.55 & 7.16 & 1.48 & 1.16 & & \\
\hline & $P_{W C}$ & 313 & 15.48 & 19.11 & 0.66 & 0.95 & 13.66 & 11.83 & 10.01 & 47.18 & 46.86 & $4.97^{*}$ & 0.07 \\
\hline Financial & $P_{W I}$ & 313 & 13.90 & 16.77 & 0.65 & 1.12 & 12.49 & 11.09 & 9.68 & 11.67 & 11.35 & $6.48^{* *}$ & 0.03 \\
\hline & $P_{M C A P}$ & 313 & 10.36 & 16.68 & 0.45 & 0.58 & 8.97 & 7.58 & 6.19 & 1.48 & 1.16 & & \\
\hline
\end{tabular}

Table 7: Out of sample market-timed portfolio performance (October '89 to November '15): results for the win-weighted portfolio $P_{W I}$, the market cap portfolio, $P_{M C A P}$, and the momentum timing strategy that switches between both, $P_{W C}$. All numbers, including returns, are reported net of transaction costs of $25 \mathrm{bps}$ deducted monthly from the raw returns using the appropriate portfolio turnover figures. 


\begin{tabular}{|c|c|c|c|c|c|c|c|c|c|c|}
\hline Row \# & Portfolio & Investment Universe & $\begin{array}{c}\text { intercept } \\
\text { (Annualized \%) }\end{array}$ & $\beta_{M K T}$ & $\beta_{S M B}$ & $\beta_{H M L}$ & $\beta_{R M W}$ & $\beta_{C M A}$ & $\beta_{\text {Момо }}$ & $\beta_{L I Q}$ \\
\hline 1. & $P_{M K T}$ & All Stocks & $\begin{array}{l}4.17^{* * *} \\
(0.00)\end{array}$ & $\begin{array}{l}0.99^{* * *} \\
(0.00)\end{array}$ & $\begin{array}{c}0.00 \\
(0.59)\end{array}$ & $\begin{array}{l}0.05^{* * *} \\
(0.00)\end{array}$ & $\begin{array}{l}0.06^{* * *} \\
(0.00)\end{array}$ & $\begin{array}{l}0.03^{*} \\
(0.07)\end{array}$ & $\begin{array}{l}-0.00 \\
(0.83)\end{array}$ & $\begin{array}{l}-0.00 \\
(0.91)\end{array}$ \\
\hline 2. & $P_{M K T}$ & Ind. winners excl. & $\begin{array}{l}3.72^{* * *} \\
(0.00)\end{array}$ & $\begin{array}{l}0.99^{* * *} \\
(0.00)\end{array}$ & $\begin{array}{c}0.00 \\
(0.59)\end{array}$ & $\begin{array}{l}0.05^{* * *} \\
(0.00)\end{array}$ & $\begin{array}{l}0.07^{* * *} \\
(0.00)\end{array}$ & $\begin{array}{l}0.03^{*} \\
(0.07)\end{array}$ & $\begin{array}{l}-0.00 \\
(0.83)\end{array}$ & $\begin{array}{l}-0.00 \\
(0.91)\end{array}$ \\
\hline 3. & $P_{S M B}$ & All Stocks & $\begin{array}{l}4.05^{* *} \\
(0.02)\end{array}$ & $\begin{array}{c}-0.23^{* * *} \\
(0.00)\end{array}$ & $\begin{array}{l}0.70^{* * *} \\
(0.00)\end{array}$ & $\begin{array}{c}0.07 \\
(0.29)\end{array}$ & $\begin{array}{l}-0.16^{* *} \\
(0.02)\end{array}$ & $\begin{array}{l}-0.08 \\
(0.43)\end{array}$ & $\begin{array}{c}-0.18^{* * *} \\
(0.00)\end{array}$ & $\begin{array}{l}-0.00 \\
(0.15)\end{array}$ \\
\hline 4. & $P_{S M B}$ & Ind. winners excl. & $\begin{array}{c}-4.01^{* *} \\
(0.01)\end{array}$ & $\begin{array}{c}-0.24^{* * *} \\
(0.00)\end{array}$ & $\begin{array}{c}0.66^{* * *} \\
(0.00)\end{array}$ & $\begin{array}{c}0.07 \\
(0.26)\end{array}$ & $\begin{array}{c}-0.15^{* *} \\
(0.02)\end{array}$ & $\begin{array}{l}-0.08 \\
(0.37)\end{array}$ & $\begin{array}{c}-0.17^{* * *} \\
(0.00)\end{array}$ & $\begin{array}{l}-0.00 \\
(0.22)\end{array}$ \\
\hline 5. & $P_{S M B}$ & All Stocks & $\begin{array}{l}6.17^{* * *} \\
(0.00)\end{array}$ & $\begin{array}{c}-0.14^{* * *} \\
(0.00)\end{array}$ & - & $\begin{array}{c}0.11 \\
(0.14)\end{array}$ & $\begin{array}{c}-0.47^{* * *} \\
(0.00)\end{array}$ & $\begin{array}{l}-0.18 \\
(0.12)\end{array}$ & $\begin{array}{c}-0.16^{* * *} \\
(0.00)\end{array}$ & $\begin{array}{c}-0.00^{* *} \\
(0.04)\end{array}$ \\
\hline 6. & $P_{S M B}$ & Ind. winners excl. & $\begin{array}{l}-2.02 \\
(0.29)\end{array}$ & $\begin{array}{c}-0.16^{* * *} \\
(0.00)\end{array}$ & - & $\begin{array}{c}0.11 \\
(0.13)\end{array}$ & $\begin{array}{c}-0.44^{* * *} \\
(0.00)\end{array}$ & $\begin{array}{l}-0.18 \\
(0.10)\end{array}$ & $\begin{array}{c}-0.15^{* * *} \\
(0.00)\end{array}$ & $\begin{array}{l}-0.00^{*} \\
(0.06)\end{array}$ \\
\hline 7. & $P_{S}$ & All Stocks & $\begin{array}{l}8.74^{* * *} \\
(0.00)\end{array}$ & $\begin{array}{l}0.76^{* * *} \\
(0.00)\end{array}$ & $\begin{array}{l}1.09^{* * *} \\
(0.00)\end{array}$ & $\begin{array}{c}0.17^{* * *} \\
(0.01)\end{array}$ & $\begin{array}{l}-0.10 \\
(0.11)\end{array}$ & $\begin{array}{l}-0.02 \\
(0.79)\end{array}$ & $\begin{array}{c}-0.23^{* * *} \\
(0.00)\end{array}$ & $\begin{array}{l}-0.00 \\
(0.28)\end{array}$ \\
\hline 8. & $P_{S}$ & Ind. winners excl. & $\begin{array}{l}-0.02 \\
(0.99)\end{array}$ & $\begin{array}{l}0.75^{* * *} \\
(0.00)\end{array}$ & $\begin{array}{l}1.05^{* * *} \\
(0.00)\end{array}$ & $\begin{array}{l}0.18^{* * *} \\
(0.00)\end{array}$ & $\begin{array}{l}-0.09 \\
(0.14)\end{array}$ & $\begin{array}{l}-0.03 \\
(0.75)\end{array}$ & $\begin{array}{c}-0.22^{* * *} \\
(0.00)\end{array}$ & $\begin{array}{l}-0.00 \\
(0.46)\end{array}$ \\
\hline 9. & $P_{S}$ & All Stocks & $\begin{array}{c}12.03^{* * * *} \\
(0.00)\end{array}$ & $\begin{array}{c}0.89^{* * *} \\
(0.00)\end{array}$ & - & $\begin{array}{c}0.24^{* * *} \\
(0.01)\end{array}$ & $\begin{array}{c}-0.58^{* * *} \\
(0.00)\end{array}$ & $\begin{array}{l}-0.18 \\
(0.17)\end{array}$ & $\begin{array}{c}-0.19^{* * *} \\
(0.00)\end{array}$ & $\begin{array}{c}-0.00^{*} \\
(0.06)\end{array}$ \\
\hline 10. & $P_{S}$ & Ind. winners excl. & $\begin{array}{c}3.16 \\
(0.15)\end{array}$ & $\begin{array}{l}0.88^{* * *} \\
(0.00)\end{array}$ & - & $\begin{array}{c}0.24^{* * *} \\
(0.00)\end{array}$ & $\begin{array}{c}-0.55^{* * *} \\
(0.00)\end{array}$ & $\begin{array}{l}-0.18 \\
(0.16)\end{array}$ & $\begin{array}{c}-0.19^{* * *} \\
(0.00)\end{array}$ & $\begin{array}{c}-0.00^{*} \\
(0.10)\end{array}$ \\
\hline 11. & $F F_{S M B}$ & All Stocks & $\begin{array}{l}3.02^{* *} \\
(0.04)\end{array}$ & $\begin{array}{c}0.12^{* * *} \\
(0.00)\end{array}$ & - & $\begin{array}{c}0.06 \\
(0.29)\end{array}$ & $\begin{array}{c}-0.44^{* * *} \\
(0.00)\end{array}$ & $\begin{array}{c}-0.14^{*} \\
(0.09)\end{array}$ & $\begin{array}{c}0.04 \\
(0.20)\end{array}$ & $\begin{array}{l}-0.00 \\
(0.11)\end{array}$ \\
\hline 12. & $F F_{S M B}^{*}$ & Ind. winners excl. & $\begin{array}{c}1.56 \\
(0.29)\end{array}$ & $\begin{array}{c}0.14^{* * *} \\
(0.00)\end{array}$ & - & $\begin{array}{l}0.12^{*} \\
(0.05)\end{array}$ & $\begin{array}{c}-0.53^{* * *} \\
(0.00)\end{array}$ & $\begin{array}{l}-0.14 \\
(0.10)\end{array}$ & $\begin{array}{c}0.04 \\
(0.16)\end{array}$ & $\begin{array}{l}-0.00 \\
(0.13)\end{array}$ \\
\hline
\end{tabular}

Table 8: Market-Wide Regressions: Regression results for: the cap-weighted market portfolio of our investment universe, $P_{M K T}$; our small minus big portfolio $P_{S M B}$; our small portfolio $P_{S}$; the original Fama \& French size factor, $F F_{S M B}$, constructed from all stocks, and a reconstruction of the Fama \& French size factor, $F F_{S M B}^{*}$, with industry winners excluded, against 7 risk factors. The 7 risk factors are: $M K T$, the size factor: $S M B$, a value factor: $H M L$, an operating profitability factor $R M W$, an investment factor $C M A$, a momentum factor $M O M O$, and a liquidity factor $L I Q$. Portfolios are constructed in two investment universes, the first including all stocks and the second where industry winning stocks have been removed. P-values are underneath the parameter estimates in brackets. Where the $\beta_{S M B}$ value is missing the Fama French SMB factor is excluded from the regression to allow the dependent variable intercept to capture a size premium. The regressions are run over the full sample period (Jul '63 - Nov '15). 

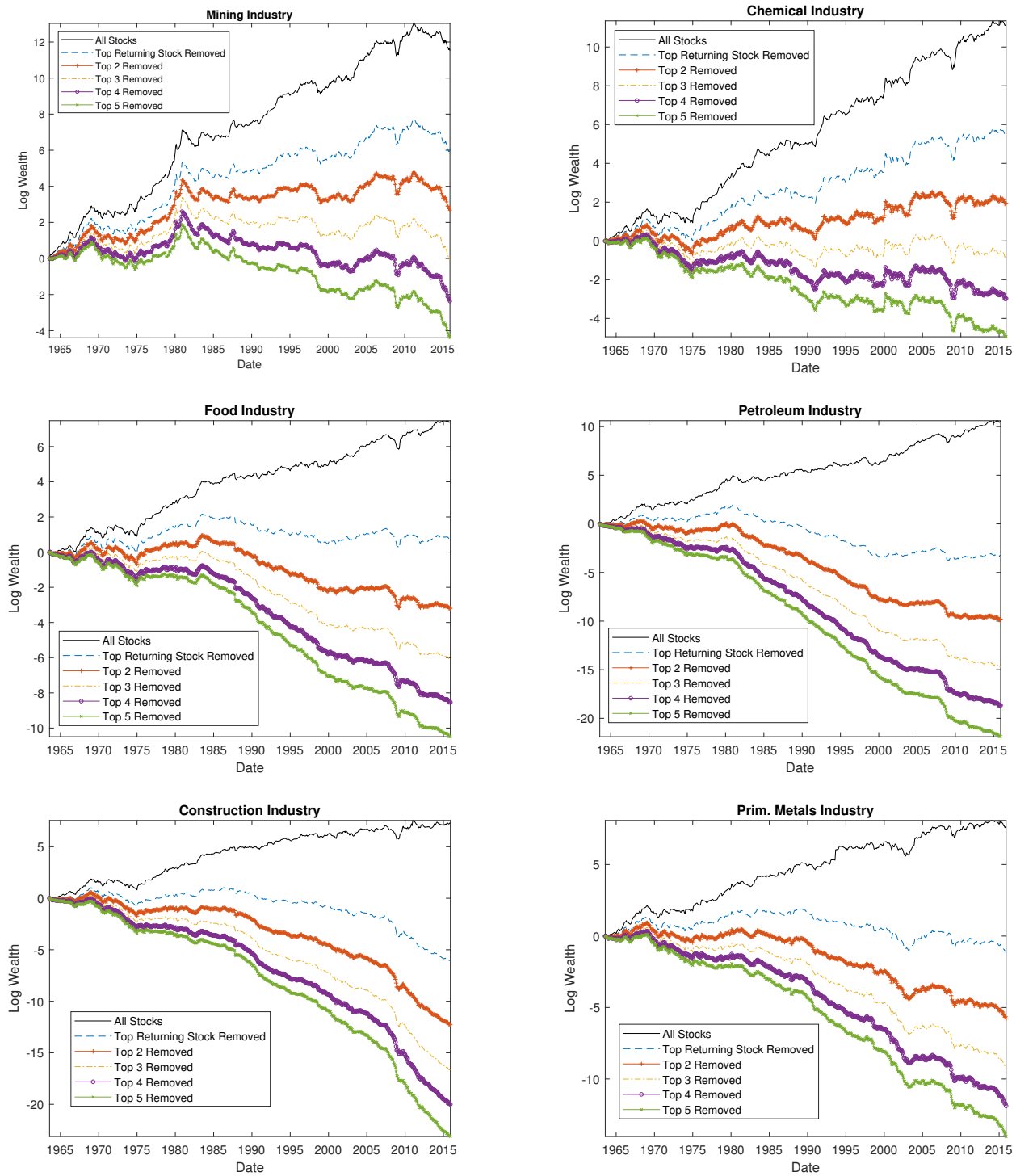

Figure 1:

The log wealth resulting from investment in an equally-weighted portfolio constructed from the bottom third of stocks ranked by size in some sample industries. Each portfolio is re-balanced monthly and constructed from a data set excluding with hindsight the best $J$ stocks from the industry each month, for $J$ in the range 0 to 5 . The returns demonstrate the dependence of the small capitalization portfolios on the best ex-post performing stocks. Outside of the top two performing stocks the average returns to all of the small capitalization portfolios are negative. 

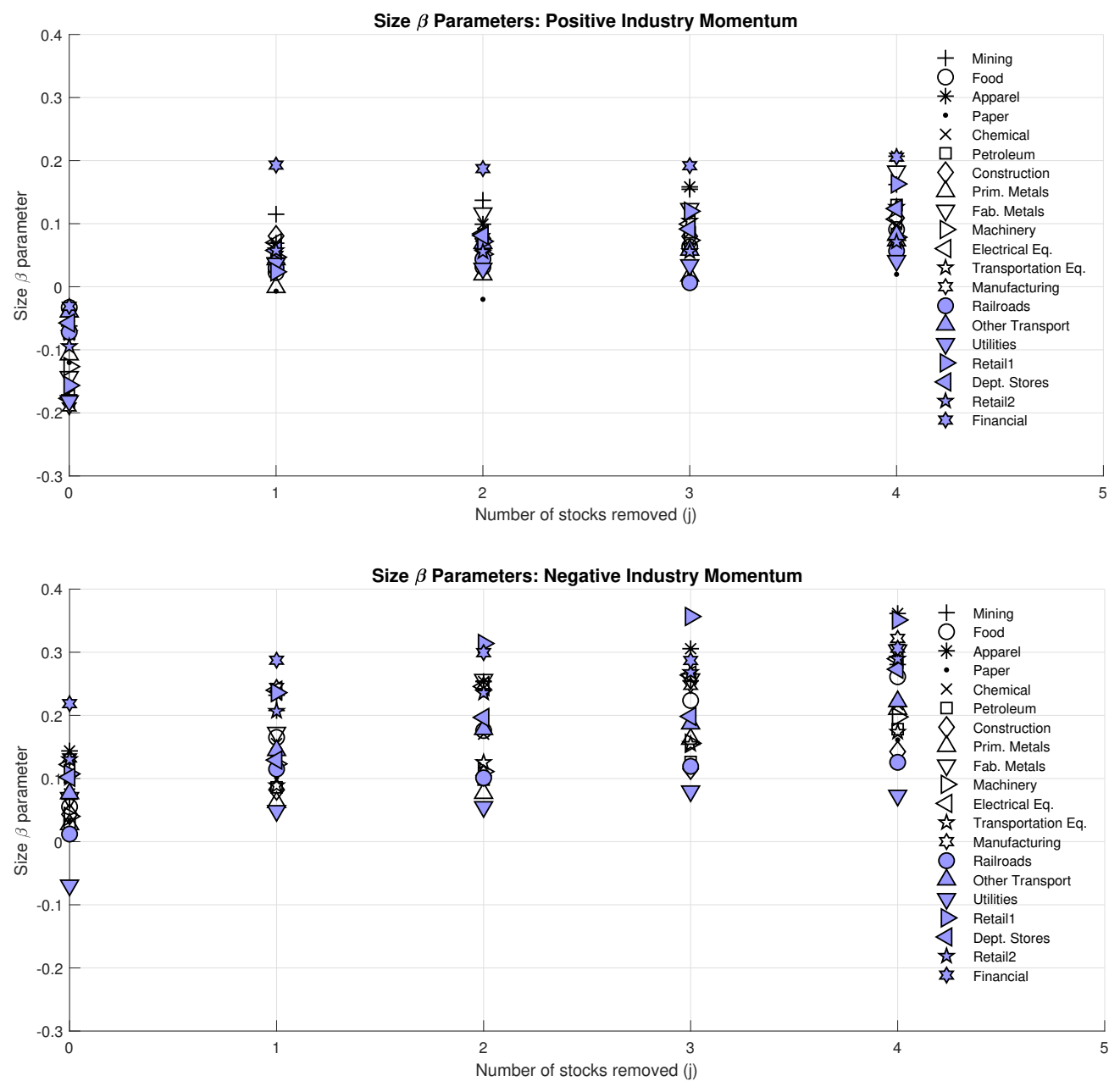

Figure 2:

The value of each estimated coefficient, $\beta_{j}$, across the 20 industry groups, with $\mathrm{j}=0$ to 4 best performing stocks removed. Results are displayed in (a.) positive and (b.) negative industry momentum regimes. 
(a.)

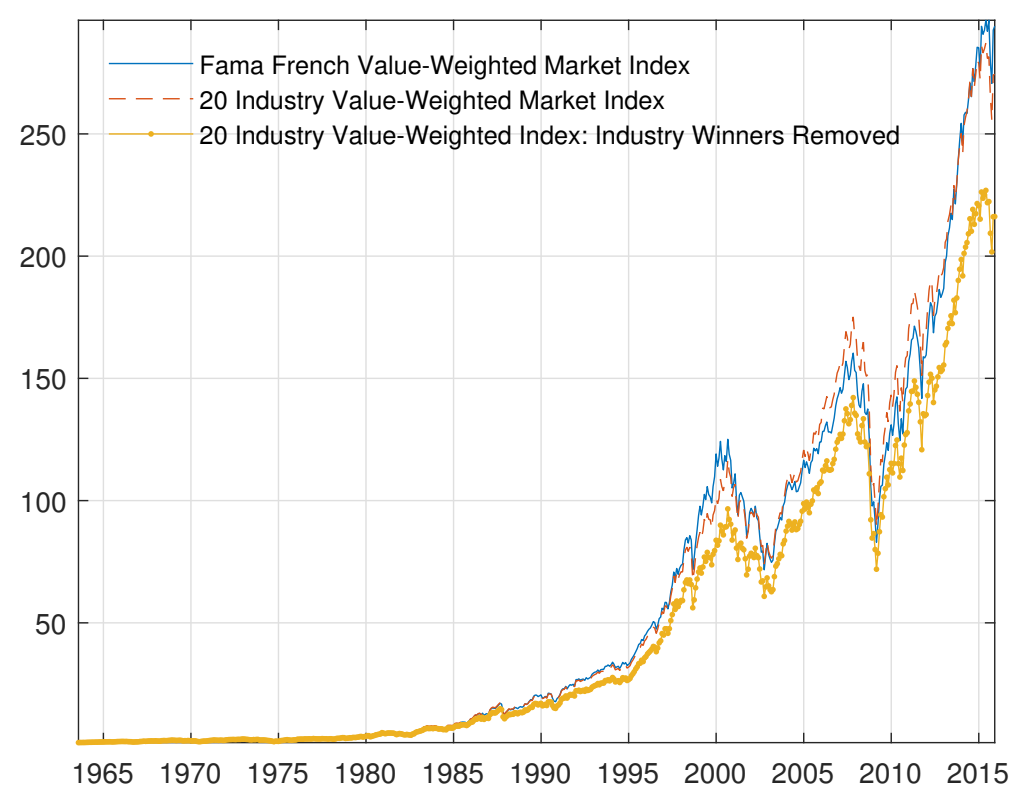

(b.)

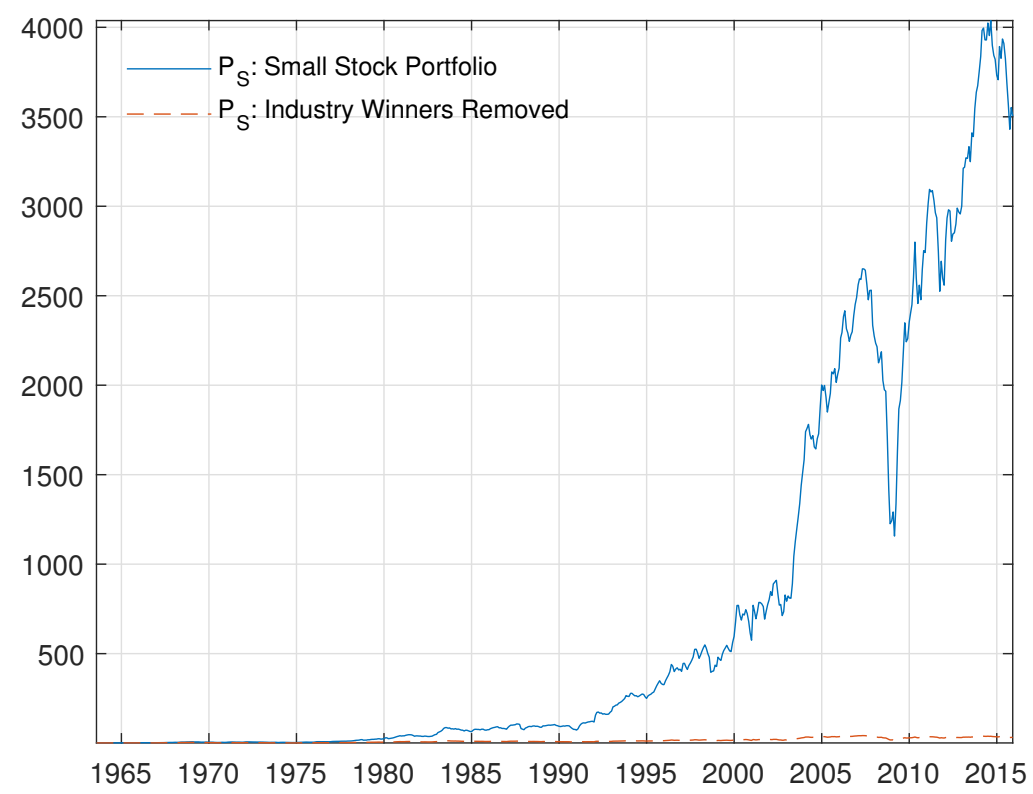

Figure 3:

Cumulative wealth (starting from one unit) from investing in: (a.) the value weighted market portfolio constructed from stocks in the 20 industries defined by SIC and the same data set excluding one industry-winning stock for each industry each month and

(b.) the long-only size portfolio consisting of the smallest third of stocks in the 20 industry data set: 1 . with all stocks included and 2 . when industry winning stocks are excluded. The results are illustrated over the full sample period (Jul '63 to Nov '15). 